\title{
Seed dormancy and germination-emerging mechanisms and new hypotheses
}

\author{
Hiroyuki Nonogaki* \\ Department of Horticulture, Oregon State University, Corvallis, OR, USA
}

\section{Edited by:}

Paolo Sabelli, University of Arizona USA

\section{Reviewed by:}

Joanna Putterill, University of

Auckland, New Zealand

Pablo Daniel Jenik, Franklin and

Marshall College, USA

*Correspondence:

Hiroyuki Nonogaki, Department of

Horticulture, Oregon State

University, 4017 ALS Bldg., Corvallis

OR 97331, USA

e-mail: hiro.nonogaki@

oregonstate.edu
Seed dormancy has played a significant role in adaptation and evolution of seed plants. While its biological significance is clear, molecular mechanisms underlying seed dormancy induction, maintenance and alleviation still remain elusive. Intensive efforts have been made to investigate gibberellin and abscisic acid metabolism in seeds, which greatly contributed to the current understanding of seed dormancy mechanisms. Other mechanisms, which might be independent of hormones, or specific to the seed dormancy pathway, are also emerging from genetic analysis of "seed dormancy mutants." These studies suggest that chromatin remodeling through histone ubiquitination, methylation and acetylation, which could lead to transcription elongation or gene silencing, may play a significant role in seed dormancy regulation. Small interfering RNA and/or long non-coding RNA might be a trigger of epigenetic changes at the seed dormancy or germination loci, such as DELAY OF GERMINATION1. While new mechanisms are emerging from genetic studies of seed dormancy, novel hypotheses are also generated from seed germination studies with high throughput gene expression analysis. Recent studies on tissue-specific gene expression in tomato and Arabidopsis seeds, which suggested possible "mechanosensing" in the regulatory mechanisms, advanced our understanding of embryo-endosperm interaction and have potential to re-draw the traditional hypotheses or integrate them into a comprehensive scheme. The progress in basic seed science will enable knowledge translation, another frontier of research to be expanded for food and fuel production.

Keywords: chromatin remodeling, dormancy, embryo, endosperm, germination, hormone

\section{INTRODUCTION}

The ultimate role of seeds is to produce offspring and maintain species. Therefore, plants have evolved diverse strategies to ensure successful germination of this genetic delivery system. Proper distribution of seed germination, in both temporal and spatial manners, is critical for survival and proliferation of seed plants. Spatial distribution of germination is generally controlled through seed and fruit morphology, which enhances dispersal of the offspring from the maternal habitat. In contrast, temporal distribution of germination is controlled mainly by the physiological status of seeds. A variation among individual seeds in a population, in terms of physiological status, allows each seed to germinate at a different timing, which is an important strategy for seeds to avoid competition with their siblings or extinction of all individuals due to a disastrous condition. Plants have evolved seed dormancy, temporal suppression of germination under the conditions favorable to germination. Induction of seed dormancy during the maturation stage and its release at a dry state after a certain period of time, which is called "after-ripening," are widespread phenomena observed in diverse species of seed plants (Bewley et al., 2013). There may be a universal mechanism of seed dormancy as well as a species-specific variation in the regulatory mechanisms.

Hormonal regulation may be a highly conserved mechanism of seed dormancy among seed plants. Induction and maintenance of seed dormancy by abscisic acid (ABA) and dormancy release by gibberellin (GA) are observed in many species. The molecular mechanism of antagonistic function of these two hormones was unclear for many years. However, identification of the rate-limiting hormone metabolism genes, such as nine-cisepoxycarotenoid dioxygenase (NCED), an ABA biosynthesis gene and GA2ox, a GA deactivation gene, and intensive analysis of their regulatory mechanisms in the last decade, have provided a comprehensive picture of $\mathrm{ABA}$ and $\mathrm{GA}$ involvement in the seed dormancy mechanisms (Seo et al., 2009). Now, we understand that seed response to light, which varies depending on species, is also controlled through hormone metabolism and signal transduction (Seo et al., 2009). Progress in seed dormancy and germination research is well summarized in recent review articles and textbooks (Graeber et al., 2012; Arc et al., 2013; Bewley et al., 2013). In this review, the main focus will be placed on the most recent discoveries from on-going research of seed dormancy and germination. Therefore, the contents of this review are not meant to be comprehensive but will highlight the "emerging" mechanisms and new hypotheses at the frontier of research.

\section{EMERGING MECHANISMS OF SEED DORMANCY}

Previously unknown seed dormancy-associated factors are emerging from on-going research, some of which enhance seed dormancy while others negatively affect it. The positive and 
negative regulators of seed dormancy, which will be discussed in this section, are summarized in Table 1. There is a risk of over-simplifying gene function with the categorization of positive and negative regulators, because there are complex regulatory mechanisms of seed dormancy, in which a single gene product could exert both positive and negative effects, including negative feedback from a positive regulator. However, to highlight the discoveries of gene function in the original research, this categorization will be used for the discussion in this section.

\section{POSITIVE REGULATION \\ DOG1-CENTRAL TO SEED DORMANCY BUT UNKNOWN FOR BIOCHEMICAL FUNCTION}

Quantitative trait locus (QTL) analysis using natural variation in Arabidopsis has identified the "seed dormancy-specific" loci, including the DELAY OF GERMINATION (DOG) genes (AlonsoBlanco et al., 2003; Bentsink et al., 2006, 2010), although some of them might not be strictly specific to dormancy (Chiang et al., 2013). One of them, DOG1 has been characterized in detail. DOG1 is expressed in seeds during the maturation stage. Loss of function of DOG1 results in no dormancy (Bentsink et al., 2006). The genetic role of DOG1 in seed dormancy and the significance of its expression in environment sensing and adaptation have been well documented (Kronholm et al., 2012; Footitt et al., 2013, 2014).

In contrast, the biochemical and molecular function of DOG1 is still a mystery. DOG1 encodes an unknown protein, for which only limited information is available. The DOG1 cDNA shows highest similarity with a Brassica napus EST from an embryo library, however this gene also is not annotated. The protein with a known function that shows the highest similarity with DOG1 is the wheat transcription factor Histone gene Binding Protein-1b (HBP-1b) (Bentsink et al., 2006). HBP$1 \mathrm{~b}$ is a leucine zipper class transcription factor, which binds to the $\mathrm{H} 3$ hexamer motif ACGTCA in the promoter regions of wheat histone H3 genes (Mikami et al., 1989). This motif is required for transcription of the wheat $\mathrm{H} 3$ histone gene (Nakayama et al., 1989). DOG1 has also been suggested to be a transcription factor, which is supported by its localization in the nucleus (Nakabayashi et al., 2012). However, the identity between DOG1 and HBP-1b is not very high especially in the basic motifs and the heptad-repeat leucines in the leucine zipper structure (Tabata et al., 1991), which are conserved in $\mathrm{HBP}-1 \mathrm{~b}$ and other $\mathrm{H} 3$ hexamer-binding proteins, such as tobacco Activation Sequence Factor-1 (ASF-1) (Lam et al., 1989) (Figure 1). Therefore, the biochemical function of DOG1 is hardly predicted from its moderate similarity to HBP-1b. So far, direct target genes of DOG1 that are clearly linked to the seed dormancy mechanisms have not been identified, although some dormancy up-(Dup) regulated genes [e.g., At5g43580 (PR peptide), At5g45540 (unknown protein), At5g45830 (DOG1), At5g47160 (YDG/SRA domain-containing protein)] or dormancy down-(Ddown) regulated genes [At4g19700 (E3 ubiquitin ligase), At5g04220 (SYNAPTOTAGMIN3), At5g46160 (ribosomal protein)] in the DOG1 near isogenic line (NIL) have been identified (Bentsink et al., 2010).

\section{POSSIBLE MODIFICATION AND PARTNERS OF DOG1}

DOG1 transcript accumulates during the seed maturation stage with its peak around 14-16 days after pollination (DAP) (Bentsink et al., 2006), is reduced to about 20\% in freshly harvested seeds, and disappears during imbibition (Nakabayashi et al., 2012). DOG1 protein also accumulates during the maturation stage, however the protein level does not decrease toward the completion of seed maturation. As a consequence, freshly harvested seeds contain a relatively high level of DOG1 protein. The protein level still remains relatively high even after 13 weeks of after-ripening when seed dormancy is already released (Nakabayashi et al., 2012). Thus, a correlation is lacking between the amount of DOG1 protein and dormancy levels in afterripened seeds. It has been proposed that the chemical property of DOG1 protein, rather than its amount, is critical for DOG1 to maintain seed dormancy and that its alteration to a nonfunctional form during after-ripening allows seed germination (Nakabayashi et al., 2012). In fact, there is a shift in the pI (isoelectric point) of the DOG1 peptides prior to and following after-ripening (Nakabayashi et al., 2012).

Induction of DOG1 in imbibed $\operatorname{dog} 1$ mutant seeds with a heat-shock inducible system does not cause dormancy and allows 100\% germination (Nakabayashi et al., 2012). This can be explained by the lack of protein modification discussed above. When $A B I 5$, another key dormancy gene was overexpressed in Arabidopsis seeds, it was not sufficient to suppress germination. Only when the SnRK2 (Snf1-related protein kinase2), which activates ABI5, was induced in imbibed seeds, ABI5 was able to suppress seed germination (Piskurewicz et al., 2008). Therefore, it is possible that the DOG1 protein induced by the heat-shock system was missing necessary modification in the ectopic induction experiment.

Recently, a search for possible DOG1 partners was conducted through a yeast two-hybrid screen, which identified multiple proteins, including the PDF1 protein phosphatase 2A (Miatton, 2012). PDF1 expression is enriched in the vascular system of the embryo (Miatton, 2012), which mimics the DOG1 localization (Nakabayashi et al., 2012). PDF expression has its peak around 16 DAP during the maturation stage and is reduced in mature seeds, which is similar to the DOG1 expression mentioned above. Unlike the $\operatorname{dog} 1$ mutant, the $p d f 1$ loss of function mutant exhibits an enhanced seed dormancy phenotype (Miatton, 2012), suggesting that PDF1 is a negative regulator of seed dormancy and antagonizes DOG1. It is hypothesized that DOG1 requires phosphorylation to be active, in terms of its function in seed dormancy induction and maintenance, and is dephosphorylated by PDF1, which could inactivate DOG1 (Miatton, 2012). More analysis of PDF1 and other DOG1-interacting proteins will potentially provide a breakthrough in seed dormancy research.

Regardless of posttranslational modification, an alternative hypothesis to explain the lack of seed dormancy in DOG1induced $\operatorname{dog} 1$ seeds is that DOG1 functions mainly during the maturation stage and the DOG1 protein contained in mature seeds might be residual. It is possible that DOG1 affects seed dormancy through its effects on ABA levels during maturation (Nakabayashi et al., 2012). DOG1 has been proposed to function in a pathway independent of plant hormones. However, 
Table 1 | Seed dormancy associated genes described in this article.

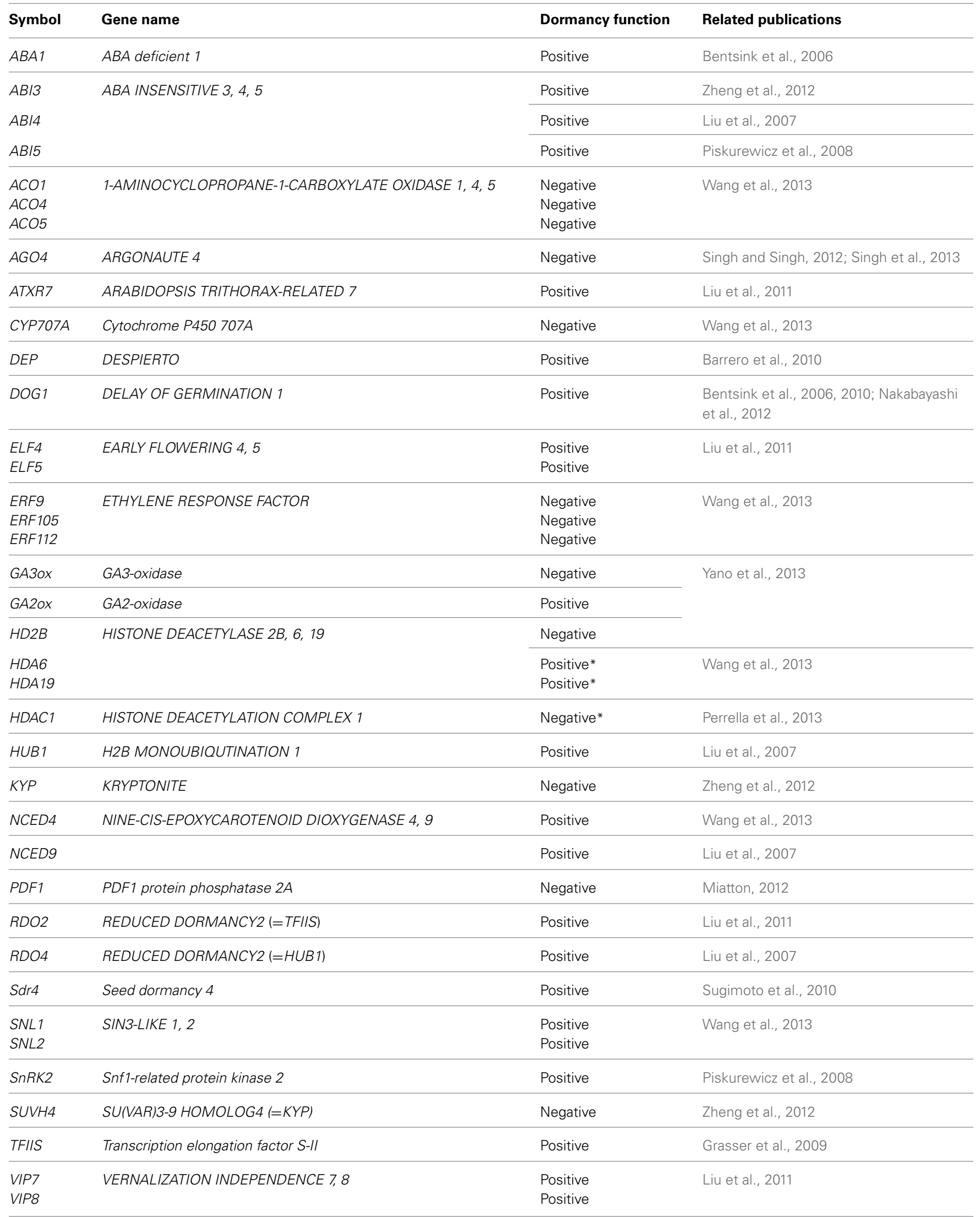

*HDA6 and HDA9 are known to affect ABA sensitivity negatively, which could affect seed dormancy negatively. 


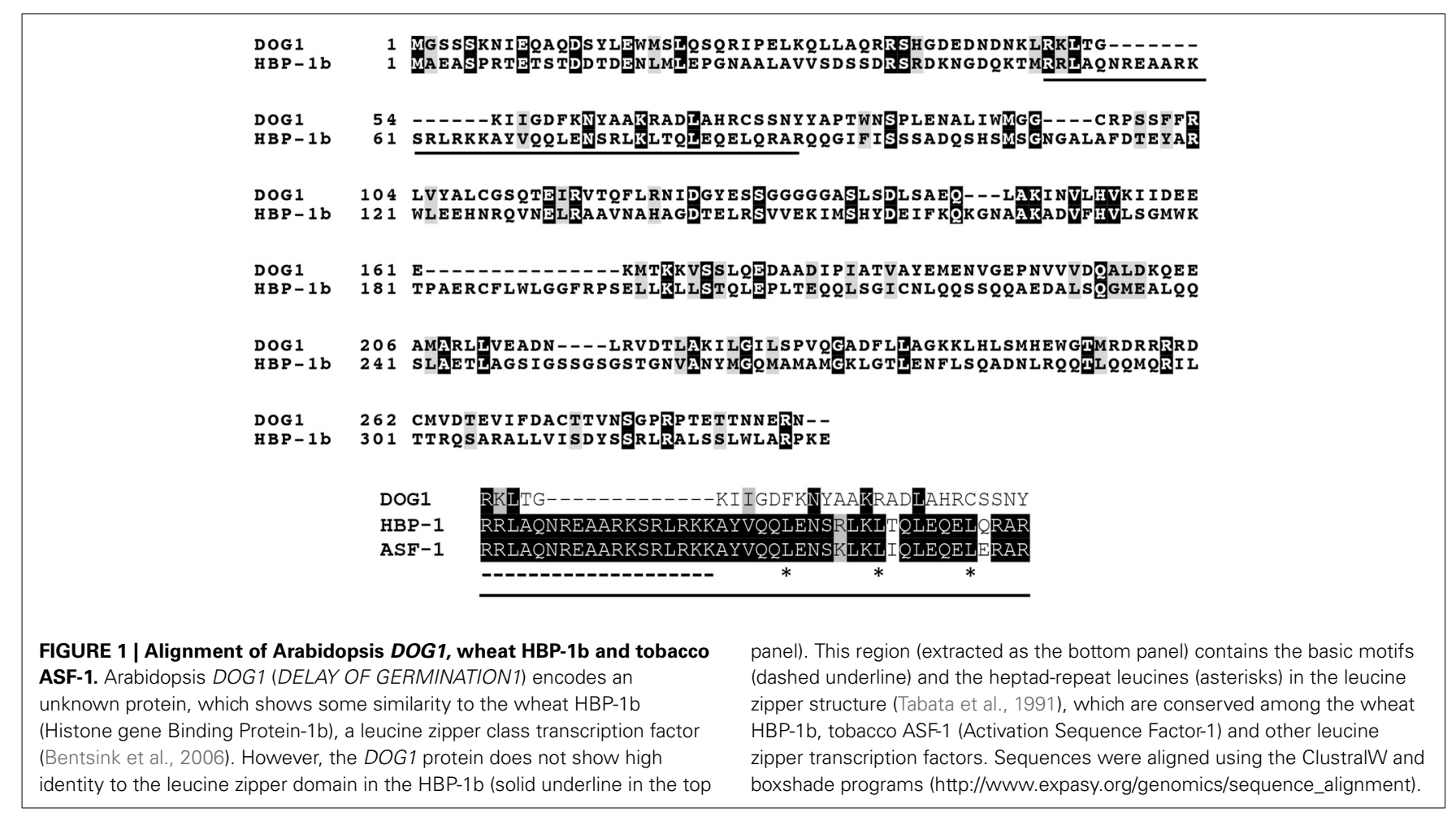

DOG1 is not able to impose seed dormancy in aba1-1, an ABAdeficient mutant (Bentsink et al., 2006), indicating that DOG1 function is dependent on ABA. ABA levels are reduced in $\operatorname{dog} 1$ mutants while GA levels are enhanced (Bentsink et al., 2006; Nakabayashi et al., 2012), supporting the idea of possible links between the DOG1 and hormone pathways in seed dormancy. More information is necessary to obtain a clear picture about the hormone dependent and independent pathways of seed dormancy. To date, induction of DOG1 specifically at the right timing during seed maturation (14-16 DAP) has not been experimentally examined. Investigation of molecular consequences upon DOG1 induction at the right timing, including gene expression, protein phosphorylation and epigenetic changes (discussed below), will provide useful information. It should be noted that there are other dormancy(-specific) genes recently discovered, such as Seed dormancy 4 (Sdr4) in rice (Sugimoto et al., 2010) and DESPIERTO in Arabidopsis (Barrero et al., 2010), which were not discussed here. Those genes also appear to be central to the dormancy mechanisms and are important targets of seed dormancy research.

\section{TRANSCRIPTION ELONGATION OF SEED DORMANCY GENES}

There is emerging evidence to suggest that regulation of transcriptional efficiency may be one of the core mechanisms of seed dormancy. Transcriptional efficiency is determined by recruitment of RNA polymerase II (Pol II) to the DNA template and the rate of transcription elongation after its binding to DNA. The efficiency of transcription elongation is influenced by an arrest of Pol II and its recovery from the arrest (Saunders et al., 2006). Transcription elongation factor S-II (TFIIS) assists Pol II to overcome the temporal arrest during elongation and enhances RNA synthesis (Kim et al., 2010) (Figure 2). A mutagenesis screen for seed dormancy in Arabidopsis yielded reduced dormancy ( $r$ do) mutants (Leon-Kloosterziel et al., 1996; Peeters et al., 2002). RDO2, one of the genes identified from this screening, encoded TFIIS (Liu et al., 2011). Another independent study also found that a mutation in TFIIS resulted in reduced seed dormancy (Grasser et al., 2009). These results suggest that transcription elongation may be a critical part of the dormancy mechanisms.

The phenotypes of other mutants also support this contention. TFIIS and Pol II interact with the Pol II-Associated Factor 1 Complex (PAF1C) (Kim et al., 2010) (Figure 2). In yeast, PAF1C consists of Paf1, Rtf1, Ctr9, Leo1, and Cdc73 (Penheiter et al., 2005; Porter et al., 2005) (Figure 2, topleft inset). The Arabidopsis orthologs of these yeast proteins EARLY FLOWERING7 (ELF7) (= Paf1), ELF8 (= Ctr9), VERNALIZATION INDEPENDENCE4 (VIP4) (=Leo1), VIP5 (= Rtf1) and PLANT HOMOLOGOUS TO PARAFIBROMIN (PHP) (= Cdc73) have been identified (Zhang and Van Nocker, 2002; He et al., 2004; Oh et al., 2004; Yu and Michaels, 2010). Seeds of the elf7, elf8, vip4, and vip5 mutants all exhibit reduced dormancy (Liu et al., 2011), suggesting the importance of PAF1C and transcription elongation for seed dormancy.

\section{HISTONE UBIQUITINATION AND METHYLATION ASSOCIATED WITH TRANSCRIPTION ELONGATION}

PAF1C interacts with Bre1, a protein involved in histone $2 \mathrm{~B}(\mathrm{H} 2 \mathrm{~B})$ monoubiquitination (Kim et al., 2009) (Figure 2). Interestingly, rdo4, another reduced dormancy mutant in Arabidopsis, which was isolated from the same mutagenesis screening as mentioned above, has a mutation in H2B MONOUBIQUITINATION1 (HUB1) gene, an Arabidopsis ortholog of Bre1 (Liu et al., 2007). 


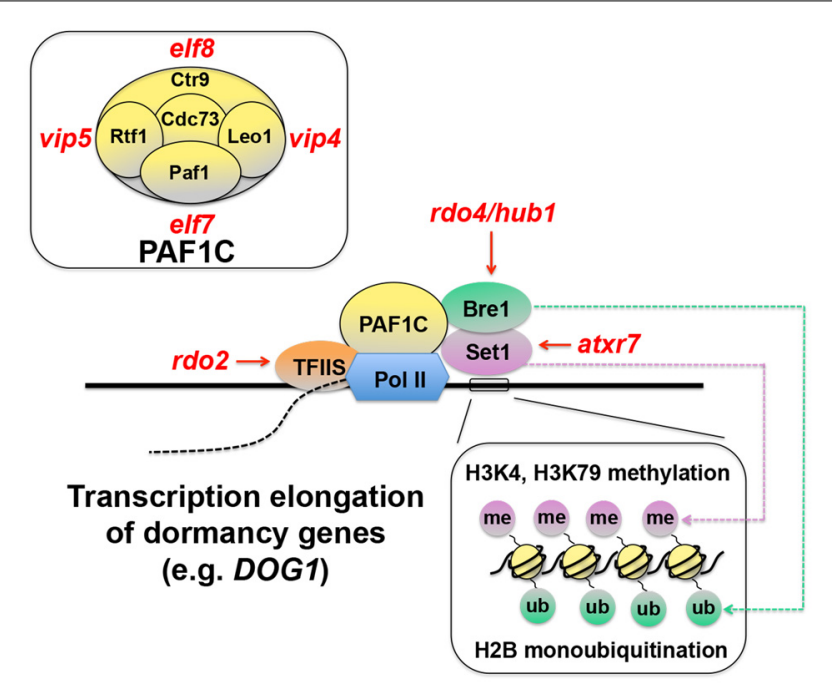

FIGURE 2 | Schematic representation of transcription elongation of seed dormancy genes. Transcription elongation factor S-II (TFIIS) assists RNA polymerase II (Pol II) and promotes transcription elongation (Saunders et al., 2006; Kim et al., 2010). Pol Il-Associated Factor 1 Complex (PAF1C), which consists of Paf1, Rtf1, Ctr9, Leo1, and Cdc73 (top-left inset) in yeast (Porter et al., 2005), also functions in this process through its interaction with Bre1, which monoubiquitinates (ub) histone 2B (H2B), and Set1, which methylates (me) histone $\mathrm{H} 3$ lysine 4 (H3K4), and lysine 79 (H3K79) (bottom-right inset) (Sun and Allis, 2002; Zhu et al., 2005; Kim et al., 2009). These chromatin-remodeling events and their positive effects on transcription elongation are thought to be critical for induction of seed dormancy genes, because mutants in many of these components (rdo2, rdo4, atxr7, elf 7, elf8, vip4, and vip5) exhibit reduced seed dormancy (Liu et al., 2011). Red italic symbols indicate Arabidopsis mutants corresponding to the yeast protein components. atxr7, arabidopsis trithorax-related 7; elf, early flowering; hub1, h2b monoubiquitination 1; rdo, reduced dormancy; vip, vernalization independence.

Bre1 interacts with Set1, which methylates histone 3 lysine 4 and lysine 79 (H3K4, H3K79) (Sun and Allis, 2002; Zhu et al., 2005) and promotes gene expression (Figure 2). A mutation in the Set1 ortholog ARABIDOPSIS TRITHORAX-RELATED 7 (ATXR7) also causes reduced dormancy in seeds (Liu et al., 2011). These results reinforce the idea that regulation of transcription elongation efficiency is an essential part of seed dormancy and suggest the significance of chromatin remodeling in the regulatory mechanisms.

$\mathrm{H} 2 \mathrm{~B}$ monoubiquitination and $\mathrm{H} 3 \mathrm{~K} 4$ and $\mathrm{H} 3 \mathrm{~K} 79$ methylation, which is dependent on $\mathrm{H} 2 \mathrm{~B}$ monoubiquitination (Nakanishi et al., 2009), are thought to activate gene expression (Henry et al., 2003). Since hubl (=brel) seeds exhibit reduced dormancy, genes down-regulated in the hubl mutant are good candidates for seed dormancy-imposing genes, the expression of which is promoted through transcriptional elongation. ABA INSENSITIIVE4 (ABI4), DOG1, NINE-CISEPOXYCAROTENOID DIOXYGENASE9 (NCED9) and other genes have been identified as possible targets of HUB1/RDO4 (Liu et al., 2007). RDO2 (TFIIS) and RDO4 (HUB1), two positive regulators of transcription are induced during the same stages of seed maturation ( 18-19 DAP). There is a significant overlap between $r d o 2$ and $r d o 4$, in terms of differentially expressed genes in the mutants. These results suggest that RDO2 and RDO4 might share common targets. Intriguingly, DOG1 is one of the genes commonly down-regulated in the two mutants (Liu et al., 2011). Activation of DOG1 through chromatin remodeling and transcriptional elongation might be an important mechanism of seed dormancy.

The hypothesis that seed dormancy is regulated by the efficiency of transcription elongation of DOG1 is also supported by the recent analysis of the tfIIs mutant, in which seed dormancy is reduced but reverted to the wild-type level by an extra copy of DOG1 (Mortensen and Grasser, 2014). However, when the $h u b 1 / r d o 4$ mutant is crossed with the NIL carrying DOG1-Cvi, which causes deep seed dormancy, the resulting seeds still show dormancy at a level between hubl and DOG1-Cvi NIL. Similar results are observed when the $h u b 1 / r d o 4$ was transformed with the Cvi DOG1 genomic fragment. The incomplete alleviation of dormancy from NIL DOG1 by hubl/rdo4 mutation in both cases suggests that $H U B 1$ is not epistatic to DOG1. In contrast, the combination of hub1 and DOG3-Cvi resulted in no seed dormancy, suggesting that $H U B 1$ functions in the same pathway as DOG3 to affect seed dormancy (Liu et al., 2007). More analyses of the specific targets of epigenetic modification and transcriptional elongation will be necessary to draw a clear picture about seed dormancy regulation through these processes.

\section{REPRESSION OF SEED GERMINATION GENES THROUGH HISTONE DEACETYLATION}

While activation of dormancy genes through transcription elongation appears to be critical for dormancy induction, continuous repression of seed germination-associated genes is also probably an essential part of dormancy maintenance. There is evidence that histone deacetylation is imperative for repression of genes positively affecting seed germination. In yeast and mammals, histone deacetylase (HDAC) interacts with SWIINDEPENDENT3 (SIN3), an amphipathic helix repeat protein, removes acetyl groups from lysine in the histone tails, and creates a transcriptionally inactive state of chromatin (Kadosh and Struhl, 1998; Lai et al., 2001; Grzenda et al., 2009) (Figure 3). In Arabidopsis, SIN3-LIKE1 (SNL1) physically interacts with HDA19, an Arabidopsis HDAC ortholog, both in vitro and in planta (Wang et al., 2013). The Arabidopsis genome contains $S N L 2$, which is partially redundant to SNL1. Seeds of the snl1 snl2 double mutant exhibit reduced dormancy. A reduced dormancy phenotype is also observed in hda19 mutant seeds (Wang et al., 2013). These results indicate that SNLs and HDA19 are positive regulators of seed dormancy. It appears that proper repression of the SNL-HDA19 targets, which are most likely germinationinducing genes, through histone deacetylation is essential for normal seed dormancy. Acetylation of H3K9/18 and H3K14 is increased in the snl1 snl2 double mutant (Wang et al., 2013), which confirms that in wild-type seeds the SIN3-HDAC complex deacetylates histones and puts repressive marks on the chromatin (Richon and O'Brien, 2002) (Figure 3).

Global gene expression analysis between the snl1 snl2 double mutant and wild-type seeds with RNA sequencing identified possible targets of SNL-HDA19. Ethylene biosynthesis 


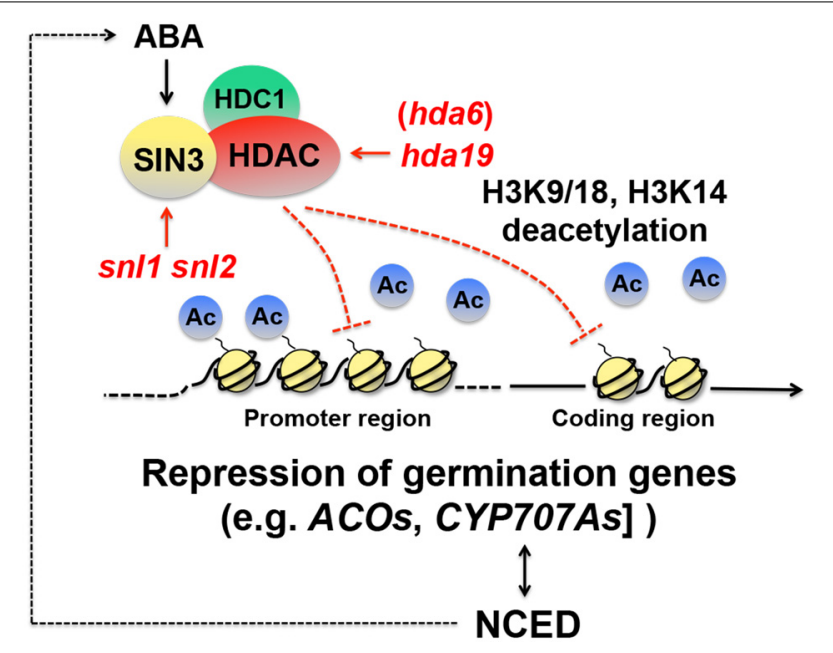

FIGURE 3 | Schematic representation of repression of seed germination genes through histone deacetylation. In yeast, a histone deacetylase (HDAC) interacts with SWI-INDEPENDENT3 (SIN3) (Kadosh and Struhl, 1998; Lai et al., 2001; Grzenda et al., 2009). HDA19, an HDAC ortholog in Arabidopsis, interacts with SIN3-LIKEs (SNLs) (Wang et al., 2013) and HDC1 (Histone Deacetylation Complex1) (Perrella et al., 2013), and removes acetyl groups (Ac) from histone 3 lysine9/18 (H3K9/18) and lysine 14 (H3K14) and represses genes positively affecting germination, such as 1-AMINOCYCLOPROPANE-1-CARBOXYLATE OXIDASES (ACOs) and CYP707As, ABA deactivation genes (Wang et al., 2013). Deacetylation occurs in both the promoter and coding regions. Both snl and hda19 mutations cause reduced dormancy (Wang et al., 2013). Expression of NCED4, an ABA biosynthesis gene, is reduced in the sn/1 sn/ 2 double mutant, suggesting that the SNL-HDA19 complex imposes seed dormancy also through the promotion of ABA biosynthesis. SNL expression is promoted by ABA (Wang et al., 2013), which suggests that there is a positive feedback loop to maintain high ABA levels through the SNL-HDA19 pathway.

genes, such as 1-AMINOCYCLOPROPANE-1-CARBOXYLATE OXIDASE1 (ACO1), ACO4, and ACO5 and ethylene response genes, such as ETHYLENE RESPONSE FACTOR9 (ERF9), ERF105, and ERF112, were up-regulated in the mutant (Wang et al., 2013). Quantitative PCR combined with chromatin immunoprecipitation with the $\mathrm{H} 3 \mathrm{~K} 9 / 18$ acetylation-specific antibodies showed that the ACOs and ERFs genes were indeed hyperacetylated in the mutant, which mainly occurred in the promoter region but were also found in the coding region (Wang et al., 2013). These results suggest that SNL-HDA19 causes seed dormancy by suppressing the ethylene pathway, which positively affects seed germination in Arabidopsis (Chiwocha et al., 2005; Arc et al., 2013).

In contrast, the same study suggests that SNL-HDA19 increases $\mathrm{ABA}$ levels and thereby enhances seed dormancy. CYP707A1 and CYP707A2, ABA deactivation genes, which reduce ABA levels, were up-regulated in the snl1 snl2 double mutants. Consistently, NCED4, an ABA biosynthesis gene, was downregulated in the same mutant (Wang et al., 2013). These results suggest that SNL-HDA19 suppresses CYP707As and activates NCED4 in wild type, both of which increase ABA levels and enhance seed dormancy. Interestingly, ABA stimulates SNL1 and SNL2 expression (Wang et al., 2013), which suggests that there is positive feedback regulation to maintain high levels of $A B A$ through the histone deacetylation pathway (Figure 3). While this study suggests that ABA levels are positively affected by SNLHDA19, other studies suggest that ABA sensitivity is negatively regulated by HDA19 (and HDA6). Mutations in HDA6 and HDA19 cause ABA hypersensitivity during germination (Chen et al., 2010; Chen and $\mathrm{Wu}, 2010$ ). Loss of function in Histone Deacetylation Complex1 (HDC1), another component of the SNL- and HDA19-containing complex, which physically interacts with HDA6 and HDA19 (Figure 3), also causes ABA hypersensitivity in seedlings. HDC1 overexpression promotes seedling emergence (Perrella et al., 2013), although detailed information about sensu stricto germination and a dormancy phenotype of the mutant seeds is not available. The significance of the opposite effects of the HDAC multiprotein complex to ABA levels (positive) and sensitivity (negative) in the regulatory mechanisms of seed dormancy is not known. It is possible that the seemingly counterintuitive effects are associated with negative feedback regulation.

\section{NEGATIVE REGULATION \\ REPRESSION OF DORMANCY GENES AND ACTIVATION OF GERMINATION GENES THROUGH HISTONE DEACETYLATION}

HISTONE DEACETYLASE 2B (HD2B), another HDAC gene, is also involved in seed dormancy. In this case, it negatively affects seed dormancy (Yano et al., 2013). This discovery was made through a combination of genome-wide association mapping (GWA) (Atwell et al., 2010) and transcriptomics. The efficiency of QTL analysis using different accessions of Arabidopsis, such as Cvi, Ler, and Col, for seed dormancy is well exemplified by the successful identification and characterization of the DOG genes (Alonso-Blanco et al., 2003; Bentsink et al., 2006, 2010). Since the comparison of a few different Arabidopsis accessions is so powerful, multiplying this approach using many accessions with natural variations in seed dormancy is expected to produce fruitful outcomes in seed dormancy research, especially when it is combined with GWA, which identified a number of single nucleotide polymorphisms (SNPs) likely associated with various phenotypes (Atwell et al., 2010). Based on this concept, 113 accessions were analyzed to identify SNPs associated with natural variation in seed dormancy using GWA and transcriptomics, which identified $H D 2 B$ as a strong candidate of a seed dormancyassociated gene. $H D 2 B$ expression levels are significantly lower in 24 dormant accessions than 28 less-dormant accessions, although there are some exceptions. When the highly dormant Cvi line was transformed with the genomic fragment of Col $H D 2 B$ (termed ${ }^{\mathrm{Col}} \mathrm{HD} 2 \mathrm{~B} / \mathrm{Cvi}$ ), mature seeds of ${ }^{\mathrm{Col}} \mathrm{HD} 2 \mathrm{~B} / \mathrm{Cvi}$ exhibited reduced dormancy, which was not evident immediately after harvest without cold stratification but became clear when seeds were stratified or partially after-ripened (Yano et al., 2013).

Cold stratification releases seed dormancy through an increase in GA levels. GA3ox1, a rate-limiting GA biosynthesis gene, is induced by cold stratification (Yamauchi et al., 2004), which triggers expansion of cortex cells in the radicle/hypocotyl region and then generates growth potential of the embryo for germination (Ogawa et al., 2003). Evidence suggests that HD2B mediates this dormancy-releasing process. In ${ }^{\mathrm{Col}} \mathrm{HD} 2 \mathrm{~B} / \mathrm{Cvi}$ seeds, expression 
of GA3ox1 and GA3ox2 and $\mathrm{GA}_{4}$ levels are increased, while expression of GA2ox2, a GA deactivation gene, is reduced compared to wild-type Cvi seeds (Yano et al., 2013). Since HDAC represses gene expression through histone deacetylation, GA2ox2 repression could be a direct effect of HD2B. In contrast, the upregulation of GA3ox genes may be through repression of their upstream regulators or some other mechanisms. It is interesting that the three separate hormone pathways (ethylene, ABA, and GA) associated with seed dormancy are regulated by histone deacetylation. These results demonstrate that epigenetic regulation through chromatin remodeling is a robust mechanism to alter hormone levels in seeds.

\section{SILENCING OF SEED DORMANCY GENES THROUGH HISTONE AND DNA METHYLATION}

The studies mentioned above showed that HDAC could affect seed dormancy either positively (HDA19) or negatively (HD2B), depending on the target genes. Histone methylation also affects seed dormancy in both ways. While H3K4 and H3K79 methylation activates gene expression and causes seed dormancy as mentioned above (Set1 or ATXR7), dimethylation of H3K9 (H3K9me2), a repressive mark, occurs on the chromatin associated with seed dormancy genes. Analysis of gene silencing at the Arabidopsis SUPERMAN (SUP) locus identified the KRYPTONITE (KYP) methyltransferase, which causes H3K9me2 (Figure 4). The methylated histone recruits the DNA methyltrasferase CHROMOMETHYLASE3 (CMT3) through its interaction with HETEROCHROMATIN PROTEIN1 (HP1) and triggers the methylation of cytosine nucleotides of DNA and silences the gene (Jackson et al., 2002; Johnson et al., 2007) (Figure 4). KYP is SU(VAR)3-9 (Rea et al., 2000) HOMOLOG 4 and is also called SUVH4. The kyp-2 mutant seeds show enhanced dormancy, suggesting that KYP/SUVH4 suppresses seed dormancy genes. Interestingly, again, DOG1 is one of the up-regulated genes in the mutant, as well as ABI3 (Zheng et al., 2012). These results suggest that histone methylation caused by KYP/SUVH4 induces silencing of DOG1 and $A B I 3$ through DNA methylation and negatively affects seed dormancy.

The KYP-CMT3 gene-silencing pathway mediates RNAdirected DNA methylation ( $\mathrm{RdDM})$, which is triggered by small interfering RNAs (siRNAs) produced by DICER-LIKE3 (DCL3) and their loading onto ARGONAUTE4 (AGO4) (Zilberman et al., 2004; Tran et al., 2005) (Figure 4). AGO proteins are components of the RNA-induced silencing complex (RISC) and are involved in gene silencing. While AGO1 and AGO10 proteins function mainly in posttranscriptional gene silencing (PTGS) through the MIR (microRNA) and TAS (trans-acting siRNA) pathways, the AGO4/AGO6/AGO9 clade proteins are associated with transcriptional gene silencing (TGS) through RdDM (Mallory and Vaucheret, 2010). Little information is available for silencing of seed dormancy genes through RdDM, however a possible involvement of AGO4 in seed dormancy regulation has been suggested from studies of cereal seed dormancy. AGO1003, an ARGONAUTE (AGO)4_9 gene in barley, is expressed differentially in the embryos of dormant and non-dormant grains and is thought to function as a negative regulator of seed dormancy through RdDM (Singh and Singh, 2012). A separate study

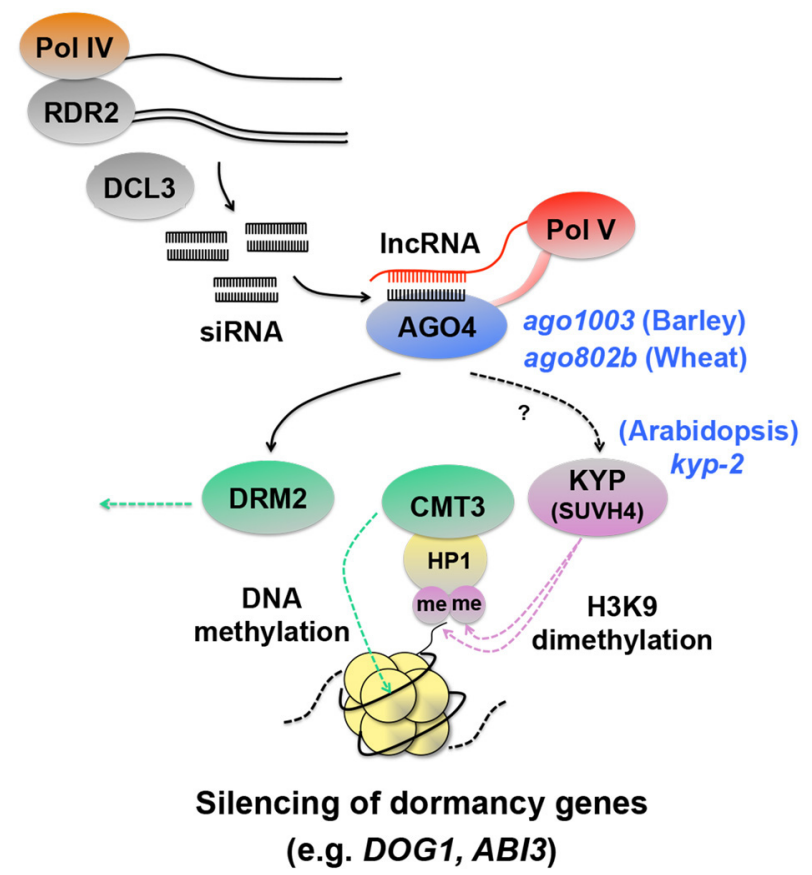

FIGURE 4 | Schematic representation of silencing of dormancy genes through histone and DNA methylation. RNA polymerase IV (Pol IV) transcripts are converted to double-stranded RNA by RNA-Dependent RNA polymerase 2 (RDR2), which are then processed into 24-nt siRNAs by DICER-LIKE3 (DCL3) (Xie et al., 2004; Herr et al., 2005; Onodera et al., 2005; Law et al., 2011). siRNAs are loaded onto ARGONAUTE4 (AGO4) (Qi et al., 2006) and interact with long non-coding RNAs (IncRNAs) produced by Pol V, which are thought to function as scaffold transcripts to guide siRNAs to specific loci to be silenced (Wierzbicki et al., 2008, 2009; Wierzbicki, 2012). In this way, the AGO4 complex containing siRNAs and IncRNAs triggers RNA-directed DNA methylation (RdDM) (Wierzbicki, 2012). A possible event downstream of AGO4 is histone 3 lysine 9 dimethylation (H3K9me2) by the KRYPTONITE (KYP), which causes HETEROCHROMATIN PROTEIN1 (HP1) to bind to the modified histone and recruit CHROMOMETHYLASE3 (CMT3), a DNA methyltransferase that induces gene silencing (Jackson et al., 2002; Zilberman et al., 2004; Tran et al., 2005; Johnson et al., 2007). A mutation in KYP in Arabidopsis causes enhanced dormancy and up-regulation of DOG1 and $A B / 3$ (Zheng et al., 2012), suggesting that the seed dormancy genes are silenced by the KYP-CMT3 pathway. The AGO4 complex is also involved in gene silencing by DOMAINS REARRANGED METHYLTRANSFERASE2 (DRM2) (Zilberman et al., 2004; Wierzbicki, 2012), although DRM2 involvement in seed dormancy regulation is not known. Direct evidence for siRNAs and IncRNAs involvement in DOG1 and $A B / 3$ regulation is lacking, however AGO4 has been shown to be a negative regulator of dormancy in barley and wheat seeds (Singh and Singh, 2012; Singh et al., 2013). The Arabidopsis, barley and wheat seed dormancy mutants corresponding to the protein components in the RdDM pathway are indicated by blue italic symbols.

in wheat supports this hypothesis. $A G O 802 B$, a wheat ortholog of AGO4_9 gene is expressed during grain development (5-20 DAP). AGO802B expression is significantly lower in preharvest sprouting (PHS)-resistant (i.e., more dormant) varieties than in susceptible ones (Singh et al., 2013). This result also suggests that $A G O 4$ is a negative regulator of dormancy. It is not known whether specific coding genes are subjected to silencing through $\mathrm{RdDM}$ in wheat seeds. However, analysis of $5 \mathrm{~S}$ 


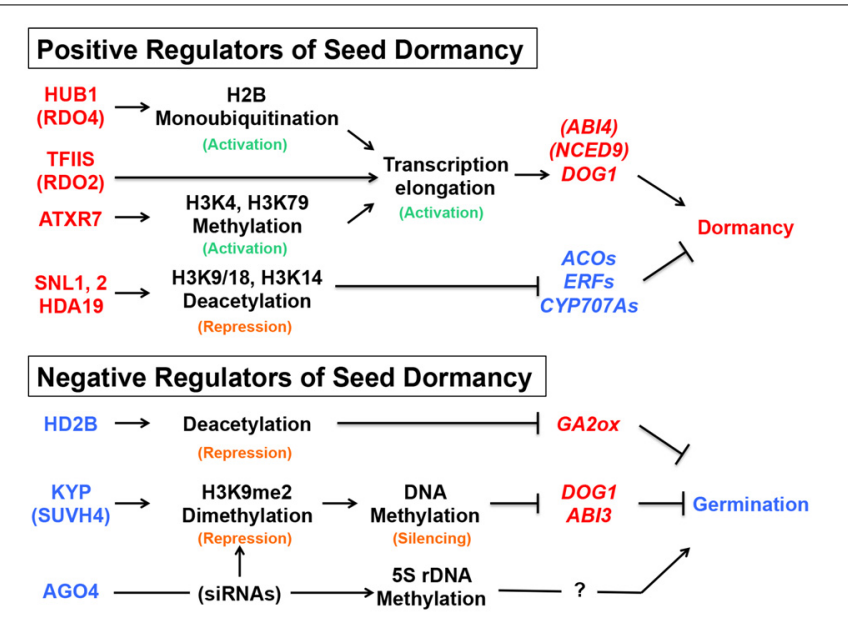

FIGURE 5 | Summary of the seed dormancy or germination pathways described in this article. The positive (red) and negative (blue) regulators of seed dormancy and their roles in the chromatin remodeling, DNA modification or siRNA pathways are indicated, together with promotive (arrows) or suppressive (blocked arrows) effects on the downstream genes (italics). Active (green) or repressive (orange) marks on histones or DNA are also indicated. See text for gene and protein symbols and references.

ribosomal DNA from PHS-resistant and susceptible varieties with the methylation-sensitive restriction enzyme MspI suggested that ribosomal DNA methylation was reduced in PHS-resistant varieties (Singh et al., 2013), supporting the hypothesis that AGO4 enhances histone and DNA methylation and acts as a negative regulator of seed dormancy.

The chromatin-remodeling factors mentioned above include both positive and negative regulators of seed dormancy, which could be considered as negative and positive regulators of seed germination, respectively. The description "activation of seed dormancy genes" or "repression of seed germination genes," which could mean the same consequence (dormancy or no germination), is confusing. It is even more confusing when the description is combined with different terminology of histone modification, such as histone (de)acetylation, monoubiquitination or (de)methylation, because they could be either repressive or active marks depending on the position of residues in the histone tail. To avoid the confusion, the positive and negative regulators of seed dormancy, their roles in chromatin and DNA modification, and possible consequences in gene expression downstream are summarized in Figure 5.

\section{NEW HYPOTHESES FOR GERMINATION EVENTS REMAINING BARRIERS OF SEED GERMINATION}

A quiescent state of the embryo is changed when molecular repression on seed germination genes is removed, which is probably orchestrated with silencing of dormancy genes. However, an active embryo is still unable to complete germination when the suppressive force, or mechanical resistance, of the covering tissues, such as the testa and endosperm, exceeds embryo growth potential. When the embryo is not dormant, it is the mechanical resistance of the covering tissues that mainly determines whether the embryo emerges from imbibed seeds.
In fact, the embryos in dormant seeds in many species are able to grow when they are excised from seeds, which is called coat-imposed dormancy (Bewley et al., 2013). While further increase in embryo growth potential may still be necessary, alteration of the properties of covering tissues plays a significant role in germination. The testa in a mature seed is generally a non-living tissue, therefore the major reduction in the mechanical resistance of the covering tissues depends on physiological changes in the living endosperm. Changes in the properties of the endosperm significantly affect timing of radicle emergence in non-dormant seeds also. Therefore, the mechanisms of endosperm weakening have been a focal point in seed germination research.

Basic information about endosperm weakening is summarized in other literature (Linkies et al., 2010; Bewley et al., 2013). Briefly, the micropylar region of endosperm (ME) surrounds the radicle tip and provides an opposing force to it (Figure 6), which is reduced during germination through weakening. The mechanical resistance of $\mathrm{ME}$ is mainly due to the thick and rigid cell walls in this tissue. Therefore, cell wall modification is thought to play an essential role in ME weakening (Bewley et al., 2013). In fact, genes encoding cell wall-modifying proteins, such as xyloglucan endotransglycosylase/hydrolases (XTHs) and expansins (EXPs), are expressed exclusively in ME of Arabidopsis (Dekkers et al., 2013), Lepidium sativum (Voegele et al., 2011) and tomato (Chen and Bradford, 2000; Chen et al., 2002) seeds during germination. While distinct cell wall architecture is observed in ME of seeds depending on plant species and family (Lee et al., 2012a), ME weakening by cell wall modifying proteins seems to be a widely conserved mechanism of germination.

\section{EMBRYO-ENDOSPERM INTERACTION IN TOMATO SEEDS}

A high throughput transcriptome analysis of germinating tomato seeds showed enrichment of cell wall-associated genes in $\mathrm{ME}$ (Martinez-Andujar et al., 2012), supporting the hypothesis discussed above. In this study, tomato seeds were dissected into the endosperm cap (EC, equivalent to $\mathrm{ME}$ ), lateral endosperm (LE), radicle-half embryo (R), and cotyledon-half embryo (C) (Figure 6A). In addition to the cell wall-associated genes, PR (pathogenesis-related) or wound-response genes were detected as another major group of ME-enriched genes. The $5^{\prime}$ upstream sequences of the ME-enriched PR genes contain the conserved sequences, including the DNA motifs targeted by ethylene response factors (ERFs). Interestingly, Tomato ERF1 (TERF1), an experimentally validated upstream regulator of the PR genes, was also one of the ME-enriched genes in tomato seeds (MartinezAndujar et al., 2012). These results suggest that TERF1 is a major upstream regulator in $\mathrm{ME}$ and induces other ME genes, such as PR- or wound response genes and possibly cell wall-associated genes also.

The degradation of cell wall in ME of tomato seeds, which is accompanied by disappearance of storage vacuoles and lipid bodies from the cells, is initiated at the inner cells adjacent to the radicle tips (Figure 6B), suggesting that $\mathrm{ME}$ activation is under the control of the embryo. A traditional view of the mechanism of ME gene induction is that diffusible signals, such as GA, or non-diffusible signals, such as peptide ligands, are secreted 


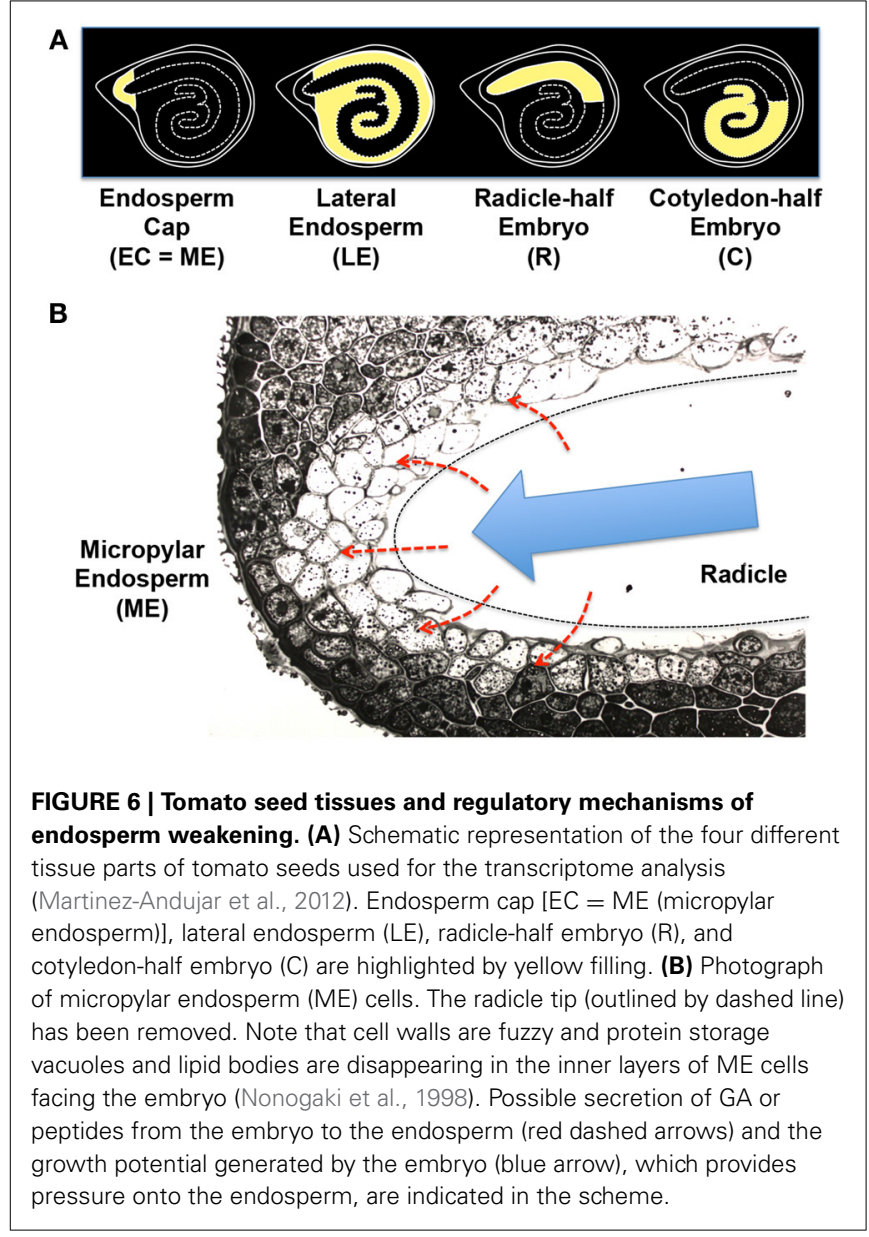

from the embryo to ME (Figure 6B, red dashed arrows) and then stimulate gene expression in this tissue. However, the new finding about the TERF1 cascade and possible involvement of a $\mathrm{PR}$ - or wounding response in $\mathrm{ME}$ gene expression generated a new hypothesis of "mechanosensing." In this hypothesis, pressure, rather than chemical molecules, which is generated by the embryo and placed onto ME cells (Figure 6B, blue arrow), triggers a wound response, TERF1 expression, and then induction of the downstream genes in ME.

\section{THE "TOUCH" GENES IN ARABIDOPSIS SEEDS}

A similar but more comprehensive and dynamic transcriptomic analysis in Arabidopsis seeds provided supporting evidence for the mechanosensing hypothesis. It is technically difficult to dissect ME from Arabidopsis seeds. Therefore, in this study gene expression was compared for the micropylar and charazal endosperm (MCE), peripheral endosperm (PE, similar to LE), radicle (RAD), and cotyledons (COT) (Dekkers et al., 2013) (Figure 7A). The high-resolution data set included many time points including those before and after testa rupture (TR) and endosperm rupture (ER), which are the signature events during germination and at the completion of germination, respectively (Figure 7B). This study demonstrated that TR was marked by activation of the specific genes in MCE, such as TOUCH3 and TOUCH4, which are
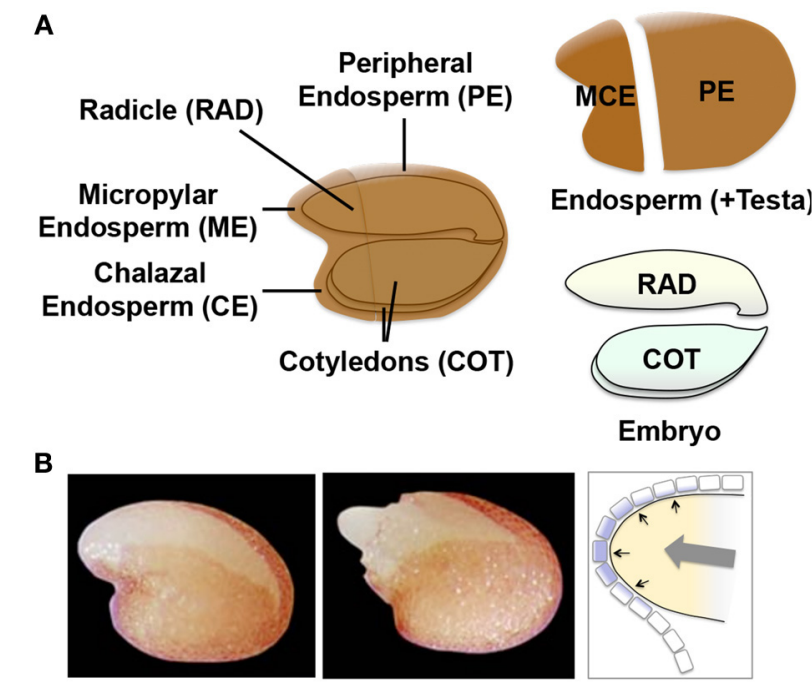

FIGURE 7 | Arabidopsis seed tissues and regulatory mechanisms of endosperm weakening. (A) Schematic representation of the four different tissue parts of Arabidopsis seeds used for the transcriptome analysis (Dekkers et al., 2013). The micropylar (ME) plus charazal (CE) endosperm (MCE), peripheral endosperm (PE, similar to $L E)$, radicle (RAD) and cotyledons (COT) are indicated in the scheme. (B) Photographs of Arabidopsis seeds at testa rupture (TR, left) and endosperm rupture (ER, right). Schematic representation of $\mathrm{ME}$ is shown to the right with the growth potential of the embryo (gray arrow) and pressure (black arrows) placed onto the single cell layer of endosperm (with purple filling).

known to be induced by touch or thigmotropism (Braam, 2005). The comparison of MCE genes at TR in Arabidopsis seeds with the genes up-regulated by touching the aerial part of Arabidopsis plants (Lee et al., 2005) showed significant overlaps. These results suggest that ME gene induction in Arabidopsis seeds is also caused by touch or mechanosensing (Dekkers et al., 2013).

No conclusive evidence has been obtained to date for the mechanosensing or touch hypothesis. However, the new findings have great potential to re-draw the traditional view of $\mathrm{ME}$ gene regulation, which is a core mechanism of germination. It is well known that GA stimulates ME gene expression in the GAdeficient gib-1 tomato seeds, which absolutely require GA for radicle emergence (Groot and Karssen, 1987; Nonogaki et al., 2000). The GA requirement for ME gene expression can be substituted by co-incubation of ME with the embryonic axes, suggesting that the embryo produces GA and secretes it to the endosperm (Groot and Karssen, 1987). There seems to be no doubt that ME gene expression is under the control of GA and the embryo. However, it should be noted that exogenous GA stimulates gene expression in both ME and LE when tomato seeds are dissected, while only ME is responsive when GA is applied to intact seeds (Martinez-Andujar et al., 2012). This raises the question as to why LE in an intact seed remains unaffected by GA or why only $\mathrm{ME}$ is responsive to it? The new hypothesis (mechanosensing or touch) could answer these questions. If the GA-dependent embryonic effects on ME gene expression are not directly exerted through chemical secretion but are indirectly mediated by the pressure provided by the radicle tip, the highly localized gene 


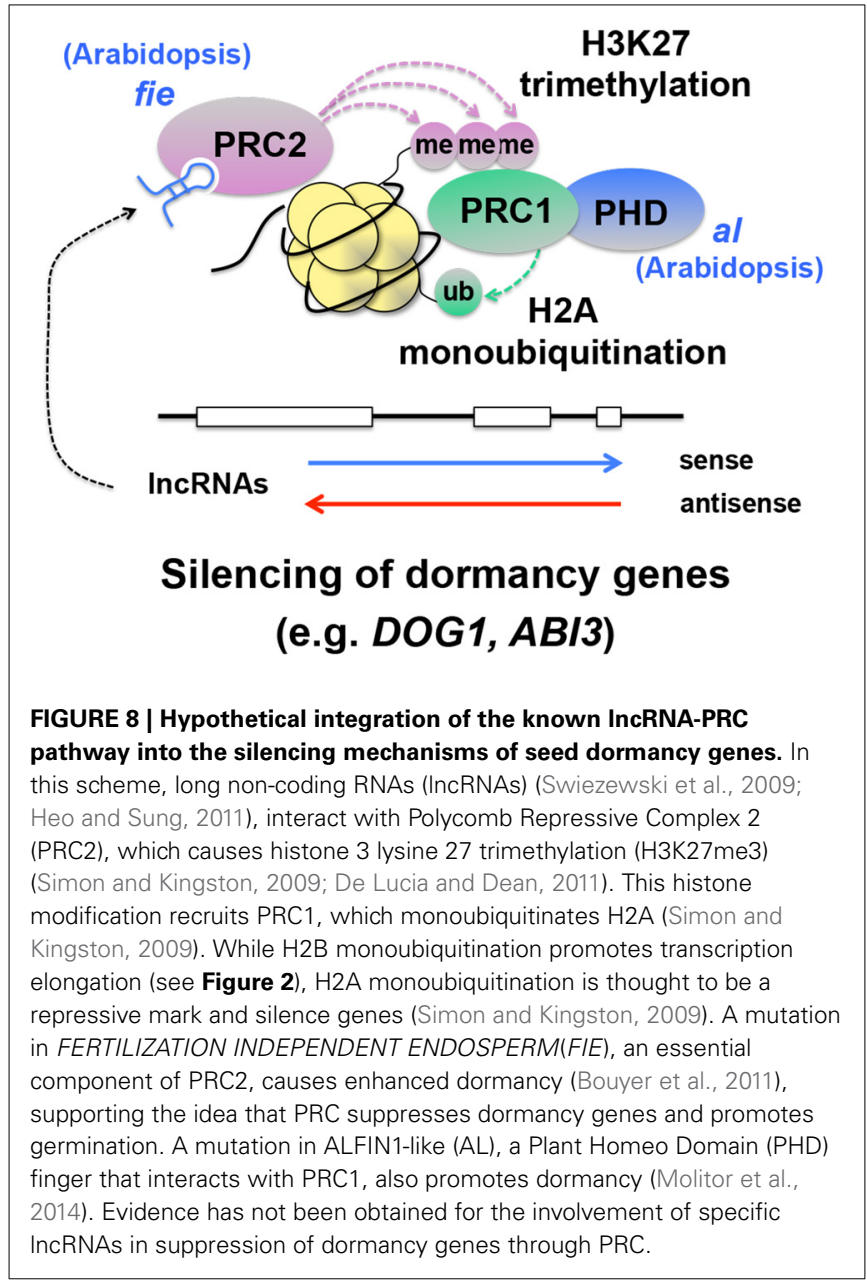

expression in ME, which is in close contact with the radicle tip, could be explained. Since generation of embryo growth potential, which causes the pressure onto ME, is dependent on GA (Ni and Bradford, 1993; Yamaguchi et al., 2001), the concept of pressure-triggered stimulation of ME gene expression is well integrated with the traditional concept (and evidence) of GA- and embryo dependency of ME gene expression. While the possibility of direct stimulation of ME by GA or insoluble secondary messengers should not be excluded, the recent data sets provided the new concept for embryo-endosperm interaction and opened the next phase of seed germination research.

\section{PERSPECTIVES FOR BASIC RESEARCH AND KNOWLEDGE TRANSLATION \\ MORE DISCOVERIES EXPECTED THROUGH EPIGENETIC STUDY}

A number of discoveries were made in the recent studies of seed dormancy and germination. More significant discoveries will probably be made from epigenetic studies of seed dormancy and germination over the next few years. While bioinformatics and systems biology could generate new hypotheses, the exciting discoveries happening from characterization of seed dormancy mutants look very convincing and promising. Exploring these emerging mechanisms with forward genetics and biochemical
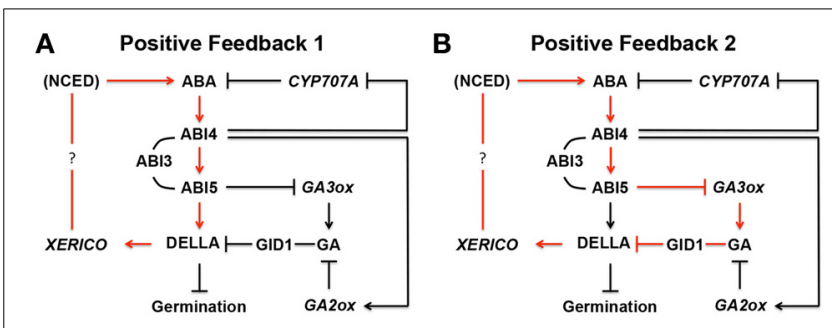

C

D

Positive Feedback 4
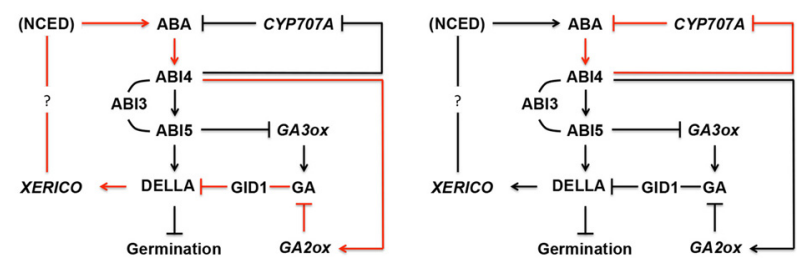

FIGURE 9 | Positive feedback loops in ABA biosynthesis in seeds. (A) In Positive Feedback 1, ABA produced by NCED, a rate-limiting ABA biosynthesis enzyme, induces $A B \mid s$. $A B \mid 3$, and $A B \mid 5$ interacts with each other while $A B \mid 4$ induces $A B \mid 5$ by binding its promoter region. $A B \mid 5$ binds to the promoter region of a DELLA gene, such as RGL2, and up-regulates its expression. DELLA then promotes expression of XERICO, which increases $A B A$ biosynthesis through unknown mechanism(s). In this way, the originally produced $A B A$ in seeds enhances $A B A$ biosynthesis through positive feedback. (B) In Positive Feedback 2, ABI5 down-regulates GA3ox, a GA biosynthesis gene, and reduces GA and GA response by GID1, a GA receptor. Reduced GA levels stabilize DELLA protein, such as RGL2, and increases ABA biosynthesis through XERICO, as described above. (C) In Positive Feedback 3, ABI4 up-regulates GA2ox, a GA deactivation gene, resulting in the same outcome as Positive Feedback 2. (D) ABI4 down regulates CYP707A, an ABA deactivation gene. Therefore, $A B A$ starts to accumulate in seeds, which further enhances the same pathway through positive feedback. In these schemes, many other components, which may be participating in the pathways, and negative feedback loops are omitted. ABI, ABA INSENSITIVE; CYP707A, CYTOCHROME P450 707A; DELLA, D (aspartic acid) $E$ (glutamic acid) $L$ (leucine) $L$ (leucine) A (alanine) protein; GA, gibberellin; GA2ox; GA 2-oxidase; GA3ox, GA 3-oxidase; GID1, GA INSENSITIVE DWARF; NCED, nine-cis-epoxycarotenoid dioxygenase; RGA, REPRESSOR OF GAI; RGL2, RGA-LIKE 2; XERICO, "XERICO" (Greek for drought tolerant). The schemes are based on Ko et al. (2006), Zentella et al. (2007), Ariizumi et al. (2008), Piskurewicz et al. (2008), Bossi et al. (2009), Lee et al. (2012b), Cantoro et al. (2013), Kong et al. (2013), Lim et al. (2013), and Shu et al. (2013).

and molecular approaches will result in more progress in seed dormancy research. The information obtained from individual mutants of chromatin remodeling was assembled into several schemes in this article to provide an overview of the frontier of this field. However, information to connect each component precisely in the schemes is still missing. For example, while histone methylation and subsequent silencing of DOG1 by DNA methylation seems likely, contribution of DCL3, AGO4, and RdDM to the DOG1-dependent dormancy pathway is not clear (Figure 4). It is possible that siRNAs and long non-coding RNAs (lncRNAs), including antisense transcripts (Yamada et al., 2003; Liu et al., 2010; Sun et al., 2013), are involved in repression of key dormancy genes. Recent studies suggest that the Polycomb Repressive Complex (PRC), which is involved in histone methylation and gene silencing, also targets DOG1 (Bouyer et al., 2011; Muller et al., 2012; Molitor et al., 2014). This is very interesting because 
PRC is known to mediate gene silencing triggered by expression of long non-coding RNA, at least in the case of the flowering gene FLOWERING LOCUS C (Swiezewski et al., 2009; De Lucia and Dean, 2011; Heo and Sung, 2011). It is possible that some dormancy genes are regulated through the lncRNA-PRC pathway (Figure 8), which could maintain dormancy genes "dormant." Missing information in the current schemes of regulatory mechanisms of seed dormancy and germination genes might already be emerging from other epigenetic studies. In addition, the current schemes, which seem to be separate pathways, could be combined with each other and integrated into a single comprehensive scheme, through more discoveries. The crosstalk between the histone deacetylation and DNA methylation pathways is known (To et al., 2011; Kim et al., 2012), however little is known about their interaction directly linked to the seed dormancy mechanisms. This might be one of the areas in which the major discoveries could be made in the future.

\section{KNOWLEDGE TRANSLATION OF SEED HORMONE BIOLOGY}

The topic of hormonal regulation of seed dormancy, such as the regulation of ABA or GA biosynthesis and deactivation enzymes by the environmental signals (e.g., light and temperature), was minimized in the discussion above, because it is well summarized elsewhere (Finkelstein et al., 2008; Seo et al., 2009) and this article focuses on emerging mechanisms and new hypotheses. Nonetheless, this is probably the area of seed biology that has been most advanced in the last decade, and from a knowledge translation point of view, this area has the greatest potential for agricultural application. For example, identification of the rate-limiting ABA biosynthesis gene NCED advanced our understanding of thermoinhibition of lettuce seed germination, which is a critical issue in agriculture. Now, we understand that thermoinhibition of germination at high temperature, which could induce secondary dormancy, is caused by NCED expression (Argyris et al., 2008, 2011). Likewise, screening of wheat populations for mutations in ABA 8' -hydroxyase, an ABA deactivation enzyme, has successfully identified the genetic lines, which are potentially resistant to PHS, another serious issue in agriculture (Chono et al., 2013). A separate screen for a mutation in the ENHANCED RESPONSE to ABA $(E R A)$ gene also isolated PHS-resistant wheat lines (Schramm et al., 2013). The information about MOTHER OF FT AND TFL1 $(M F T)$ gene, which is a recently identified member of the ABA and GA signaling pathways in Arabidopsis (Xi et al., 2010), has already been translated into wheat (Nakamura et al., 2011; Lei et al., 2013; Liu et al., 2013).

More progressive efforts are being made to translate seed hormone biology. It has been demonstrated that direct manipulation of the rate-limiting enzymes in the hormone metabolism pathways can successfully be used to alter seed performance. Silencing NCED with RNA interference can promote germination in lettuce seeds (Huo et al., 2013). In contrast, chemical induction of NCED, a single gene, was sufficient to suppress precocious germination in Arabidopsis, which can also be applied to PHS prevention in cereal crops (Martinez-Andujar et al., 2011). While the latter approach was tested in the model system Arabidopsis, the gene induction experiments in this study were performed with the chemical ligand that has been approved for field application by the U.S. Environmental Protection Agency, making the principle applicable to agriculture. Even more advanced system of NECD enhancement, which does not require chemical application, has been established recently, using a positive feedback mechanism. In this system, a chimeric NCED gene, which is designed to trigger positive feedback regulation, amplifies ABA biosynthesis and signaling in seeds and causes hyperdormancy in a spontaneous manner (Nonogaki et al., 2014). This positive feedback system was created based on the mechanisms emerged from, and the comprehensive understanding established by, the past research on the ABA metabolism and signaling pathway in seeds. The translational research unexpectedly revealed that a positive feedback mechanism is also present in the native system of NCED expression in seeds (Nonogaki et al., 2014), demonstrating the synergy between basic and translational research. Other positive feedback mechanisms in the hormonal regulation of seed dormancy and germination are also emerging from on-going discoveries (summarized in Figure 9). More findings and understanding of elegant pathways in nature will provide greater opportunities of knowledge translation, another frontier of research that should be expanded in the future.

\section{ACKNOWLEDGMENTS}

I am grateful to Roger Beachy, World Food Center, University of California, Davis, USA, for collaboration and continuous support in the translational biology projects described in this article, and Khadidiatou Sall and Mariko Nonogaki for critical reading of and helpful suggestions for the manuscript.

\section{REFERENCES}

Alonso-Blanco, C., Bentsink, L., Hanhart, C. J., Vries, H. B.-D., and Koornneef, M. (2003). Analysis of natural allelic variation at seed dormancy loci of Arabidopsis thaliana. Genetics 164, 711-729.

Arc, E., Sechet, J., Corbineau, F., Rajjou, L., and Marion-Poll, A. (2013). ABA crosstalk with ethylene and nitric oxide in seed dormancy and germination. Front. Plant Sci. 4:63. doi: 10.3389/fpls.2013.00063

Argyris, J., Dahal, P., Hayashi, E., Still, D. W., and Bradford, K. J. (2008). Genetic variation for lettuce seed thermoinhibition is associated with temperaturesensitive expression of abscisic acid, gibberellin, and ethylene biosynthesis, metabolism, and response genes. Plant Physiol. 148, 926-947. doi: 10.1104/pp.108.125807

Argyris, J., Truco, M., Ochoa, O., McHale, L., Dahal, P., Van Deynze, A., et al. (2011). A gene encoding an abscisic acid biosynthetic enzyme (LsNCED4) collocates with the high temperature germination locus Htg6.1 in lettuce (Lactuca sp.). Theor. Appl. Genet. 122, 95-108. doi: 10.1007/s00122-010-1425-3

Ariizumi, T., Murase, K., Sun, T.-P., and Steber, C. M. (2008). Proteolysisindependent downregulation of DELLA repression in Arabidopsis by the gibberellin receptor GIBBERELLIN INSENSITIVE DWARF1. Plant Cell 20, 2447-2459. doi: 10.1105/tpc.108.058487

Atwell, S., Huang, Y. S., Vilhjalmsson, B. J., Willems, G., Horton, M., Li, Y. et al. (2010). Genome-wide association study of 107 phenotypes in Arabidopsis thaliana inbred lines. Nature 465, 627-631. doi: 10.1038/nature08800

Barrero, J. M., Millar, A. A., Griffiths, J., Czechowski, T., Scheible, W. R., Udvardi, M., et al. (2010). Gene expression profiling identifies two regulatory genes controlling dormancy and ABA sensitivity in Arabidopsis seeds. Plant J. 61, 611-622. doi: 10.1111/j.1365-313X.2009.04088.x

Bentsink, L., Hanson, J., Hanhart, C. J., Blankestijn-de Vries, H., Coltrane, C., Keizer, P., et al. (2010). Natural variation for seed dormancy in Arabidopsis is regulated by additive genetic and molecular pathways. Proc. Natl. Acad. Sci. U.S.A. 107, 4264-4269. doi: 10.1073/pnas.1000410107

Bentsink, L., Jowett, J., Hanhart, C. J., and Koornneef, M. (2006). Cloning of DOG1, a quantitative trait locus controlling seed dormancy in Arabidopsis. Proc. Natl. Acad. Sci. U.S.A. 103, 17042-17047. doi: 10.1073/pnas.0607877103 
Bewley, J. D., Bradford, K. J., Hilhorst, H. W. M., and Nonogaki, H. (2013). Seeds: Physiology of Development, Germination and Dormancy. New York, NY: Springer. doi: 10.1007/978-1-4614-4693-4

Bossi, F., Cordoba, E., Dupre, P., Mendoza, M. S., Roman, C. S., and Leon, P. (2009). The Arabidopsis ABA-INSENSITIVE (ABI) 4 factor acts as a central transcription activator of the expression of its own gene, and for the induction of ABI5 and SBE2.2 genes during sugar signaling. Plant J. 59, 359-374. doi: 10.1111/j.1365-313X.2009.03877.x

Bouyer, D., Roudier, F., Heese, M., Andersen, E. D., Gey, D., Nowack, M. K., et al. (2011). Polycomb repressive complex 2 controls the embryo-to-seedling phase transition. PLoS Genet. 7:e1002014. doi: 10.1371/journal.pgen.1002014

Braam, J. (2005). In touch: plant responses to mechanical stimuli. New Phytol. 165, 373-389. doi: 10.1111/j.1469-8137.2004.01263.x

Cantoro, R., Crocco, C. D., Benech-Arnold, R. L., and Rodríguez, M. V. (2013). In vitro binding of Sorghum bicolor transcription factors ABI4 and ABI5 to a conserved region of a GA 2-OXIDASE promoter: possible role of this interaction in the expression of seed dormancy. J. Exp. Bot. 64, 5721-5735. doi: $10.1093 /$ jxb/ert347

Chen, F., and Bradford, K. J. (2000). Expression of an expansin is associated with endosperm weakening during tomato seed germination. Plant Physiol. 124, 1265-1274. doi: 10.1104/pp.124.3.1265

Chen, F., Nonogaki, H., and Bradford, K. J. (2002). A gibberellin-regulated xyloglucan endotransglycosylase gene is expressed in the endosperm cap during tomato seed germination. J. Exp. Bot. 53, 215-223. doi: 10.1093/jexbot/53.367.215

Chen, L.-T., Luo, M., Wang, Y.-Y., and Wu, K. (2010). Involvement of Arabidopsis histone deacetylase HDA6 in ABA and salt stress response. J. Exp. Bot. 61, 3345-3353. doi: 10.1093/jxb/erq154

Chen, L.-T., and Wu, K. (2010). Role of histone deacetylases HDA6 and HDA19 in ABA and abiotic stress response. Plant Signal. Behav. 5, 1318-1320. doi: 10.4161/psb.5.10.13168

Chiang, G. C., Barua, D., Dittmar, E., Kramer, E. M., de Casas, R. R., and Donohue, K. (2013). Pleiotropy in the wild: the dormancy gene DOG1 exerts cascading control on life cycles. Evolution 67, 883-893. doi: 10.1111/j.15585646.2012.01828.x

Chiwocha, S. D., Cutler, A. J., Abrams, S. R., Ambrose, S. J., Yang, J., Ross, A. R., et al. (2005). The etr1-2 mutation in Arabidopsis thaliana affects the abscisic acid, auxin, cytokinin and gibberellin metabolic pathways during maintenance of seed dormancy, moist-chilling and germination. Plant J. 42, 35-48. doi: 10.1111/j.1365-313X.2005.02359.x

Chono, M., Matsunaka, H., Seki, M., Fujita, M., Kiribuchi-Otobe, C., Oda, S., et al. (2013). Isolation of a wheat (Triticum aestivum L.) mutant in ABA $8^{\prime}$ hydroxylase gene: effect of reduced ABA catabolism on germination inhibition under field condition. Breed. Sci. 63, 104-115. doi: 10.1270/jsbbs.63.104

Dekkers, B. J., Pearce, S., van Bolderen-Veldkamp, R. P., Marshall, A., Widera, P., Gilbert, J., et al. (2013). Transcriptional dynamics of two seed compartments with opposing roles in Arabidopsis seed germination. Plant Physiol. 163, 205-215. doi: 10.1104/pp.113.223511

De Lucia, F., and Dean, C. (2011). Long non-coding RNAs and chromatin regulation. Curr. Opin. Plant Biol. 14, 168-173. doi: 10.1016/j.pbi.2010.11.006

Finkelstein, R., Reeves, W., Ariizumi, T., and Steber, C. (2008). Molecular aspects of seed dormancy. Annu. Rev. Plant Biol. 59, 387-415. doi: 10.1146/annurev.arplant.59.032607.092740

Footitt, S., Clay, H. A., Dent, K., and Finch-Savage, W. E. (2014). Environment sensing in spring-dispersed seeds of a winter annual Arabidopsis influences the regulation of dormancy to align germination potential with seasonal changes. New Phytol. 202, 929-939. doi: 10.1111/nph.12694

Footitt, S., Huang, Z., Clay, H. A., Mead, A., and Finch-Savage, W. E. (2013). Temperature, light and nitrate sensing coordinate Arabidopsis seed dormancy cycling, resulting in winter and summer annual phenotypes. Plant J. 74, 1003-1015. doi: $10.1111 /$ tpj.12186

Graeber, K. A. I., Nakabayashi, K., Miatton, E., Leubner-Metzger, G., and Soppe, W. J. J. (2012). Molecular mechanisms of seed dormancy. Plant Cell Environ. 35, 1769-1786. doi: 10.1111/j.1365-3040.2012.02542.x

Grasser, M., Kane, C. M., Merkle, T., Melzer, M., Emmersen, J., and Grasser, K. D. (2009). Transcript elongation factor TFIIS is involved in Arabidopsis seed dormancy. J. Mol. Biol. 386, 598-611. doi: 10.1016/j.jmb.2008.12.066

Groot, S. P. C., and Karssen, C. M. (1987). Gibberellins regulate seed germination in tomato by endosperm weakening: a study with gibberellin-deficient mutants. Planta 171, 525-531. doi: 10.1007/BF00392302
Grzenda, A., Lomberk, G., Zhang, J.-S., and Urrutia, R. (2009). Sin3: master scaffold and transcriptional corepressor. Biochim. Biophys. Acta. 1789, 443-450. doi: 10.1016/j.bbagrm.2009.05.007

He, Y., Doyle, M. R., and Amasino, R. M. (2004). PAF1-complex-mediated histone methylation of FLOWERING LOCUS C chromatin is required for the vernalization-responsive, winter-annual habit in Arabidopsis. Genes Dev. 18, 2774-2784. doi: 10.1101/gad.1244504

Henry, K. W., Wyce, A., Lo, W. S., Duggan, L. J., Emre, N. C., Kao, C. F., et al. (2003). Transcriptional activation via sequential histone $\mathrm{H} 2 \mathrm{~B}$ ubiquitylation and deubiquitylation, mediated by SAGA-associated Ubp8. Genes Dev. 17, 2648-2663. doi: $10.1101 /$ gad.1144003

Heo, J. B., and Sung, S. (2011). Vernalization-mediated epigenetic silencing by a long intronic noncoding RNA. Science 331, 76-79. doi: 10.1126/science.1197349

Herr, A. J., Jensen, M. B., Dalmay, T., and Baulcombe, D. C. (2005). RNA polymerase IV directs silencing of endogenous DNA. Science 308, 118-120. doi: $10.1126 /$ science. 1106910

Huo, H., Dahal, P., Kunusoth, K., McCallum, C. M., and Bradford, K. J. (2013). Expression of 9-cis-EPOXYCAROTENOID DIOXYGENASE4 is essential for thermoinhibition of lettuce seed germination but not for seed development or stress tolerance. Plant Cell 25, 884-900. doi: 10.1105/tpc.112.108902

Jackson, J. P., Lindroth, A. M., Cao, X., and Jacobsen, S. E. (2002). Control of CpNpG DNA methylation by the KRYPTONITE histone H3 methyltransferase. Nature 416, 556-560. doi: 10.1038/nature731

Johnson, L. M., Bostick, M., Zhang, X., Kraft, E., Henderson, I., Callis, J., et al. (2007). The SRA methyl-cytosine-binding domain links DNA and histone methylation. Curr. Biol. 17, 379-384. doi: 10.1016/j.cub.2007.01.009

Kadosh, D., and Struhl, K. (1998). Histone deacetylase activity of Rpd3 is important for transcriptional repression in vivo. Genes Dev. 12, 797-805. doi: 10.1101/gad.12.6.797

Kim, J., Guermah, M., McGinty, R. K., Lee, J.-S., Tang, Z., Milne, T. A., et al. (2009). RAD6-mediated transcription-coupled H2B ubiquitylation directly stimulates H3K4 methylation in human cells. Cell 137, 459-471. doi: 10.1016/j.cell.2009.02.027

Kim, J., Guermah, M., and Roeder, R. G. (2010). The human PAF1 complex acts in chromatin transcription elongation both independently and cooperatively with SII/TFIIS. Cell 140, 491-503. doi: 10.1016/j.cell.2009.12.050

Kim, J.-M., To, T. K., and Seki, M. (2012). An epigenetic integrator: new insights into genome regulation, environmental stress responses and developmental controls by HISTONE DEACETYLASE 6. Plant Cell Physiol. 53, 794-800. doi: $10.1093 / \mathrm{pcp} / \mathrm{pcs} 004$

Ko, J.-H., Yang, S. H., and Han, K.-H. (2006). Upregulation of an Arabidopsis RING-H2 gene, XERICO, confers drought tolerance through increased abscisic acid biosynthesis. Plant J. 47, 343-355. doi: 10.1111/j.1365-313X.2006.02782.x

Kong, Y., Chen, S., Yang, Y., and An, C. (2013). ABA-insensitive (ABI) 4 and ABI5 synergistically regulate $D G A T 1$ expression in Arabidopsis seedlings under stress. FEBS Lett. 587, 3076-3082. doi: 10.1016/j.febslet.2013.07.045

Kronholm, I., Pico, F. X., Alonso-Blanco, C., Goudet, J., and de Meaux, J. (2012). Genetic basis of adaptation in Arabidopsis thaliana: local adaptation at the seed dormancy QTL DOG1. Evolution 2287-2302. doi: 10.1111/j.15585646.2012.01590.x

Lai, A., Kennedy, B. K., Barbie, D. A., Bertos, N. R., Yang, X. J., Theberge, M.-C., et al. (2001). RBP1 recruits the mSIN3-histone deacetylase complex to the pocket of retinoblastoma tumor suppressor family proteins found in limited discrete regions of the nucleus at growth arrest. Mol. Cell. Biol. 21, 2918-2932. doi: 10.1128/MCB.21.8.2918-2932.2001

Lam, E., Benfey, P. N., Gilmartin, P. M., Fang, R. X., and Chua, N. H. (1989). Sitespecific mutations alter in vitro factor binding and change promoter expression pattern in transgenic plants. Proc. Natl. Acad. Sci. U.S.A. 86, 7890-7894. doi: 10.1073/pnas.86.20.7890

Law, J. A., Vashisht, A. A., Wohlschlegel, J. A., and Jacobsen, S. E. (2011). SHH1, a homeodomain protein required for DNA methylation, as well as RDR2, RDM4, and chromatin remodeling factors, associate with RNA polymerase IV. PLoS Genet. 7:e1002195. doi: 10.1371/journal.pgen.1002195

Lee, D., Polisensky, D. H., and Braam, J. (2005). Genome-wide identification of touch- and darkness-regulated Arabidopsis genes: a focus on calmodulin-like and XTH genes. New Phytol. 165, 429-444. doi: 10.1111/j.14698137.2004.01238.x

Lee, K. J., Dekkers, B. J., Steinbrecher, T., Walsh, C. T., Bacic, A., Bentsink, L., et al. (2012a). Distinct cell wall architectures in seed endosperms in representatives 
of the Brassicaceae and Solanaceae. Plant Physiol. 160, 1551-1566. doi: 10.1104/pp.112.203661

Lee, K. P., Piskurewicz, U., Tureckova, V., Carat, S., Chappuis, R., Strnad, M., et al. (2012b). Spatially and genetically distinct control of seed germination by phytochromes A and B. Genes Dev. 26, 1984-1996. doi: 10.1101/gad. 194266.112

Lei, L., Zhu, X., Wang, S., Zhu, M., Carver, B. F., and Yan, L. (2013). TaMFT-A1 is associated with seed germination sensitive to temperature in winter wheat. PLoS ONE 8:e73330. doi: 10.1371/journal.pone.0073330

Leon-Kloosterziel, K. M., van de Bunt, G. A., Zeevaart, J. A., and Koornneef, M. (1996). Arabidopsis mutants with a reduced seed dormancy. Plant Physiol. 110, 233-240. doi: 10.1104/pp.110.1.233

Lim, S., Park, J., Lee, N., Jeong, J., Toh, S., Watanabe, A., et al. (2013). ABA-INSENSITIVE3, ABA-INSENSITIVE5, and DELLAs interact to activate the expression of SOMNUS and other high-temperature-inducible genes in imbibed seeds in Arabidopsis. Plant Cell 25, 4863-4878. doi: 10.1105/tpc.113.118604

Linkies, A., Graeber, K., Knight, C., and Leubner-Metzger, G. (2010). The evolution of seeds. New Phytol. 186, 817-831. doi: 10.1111/j.1469-8137.2010.03249.x

Liu, F., Marquardt, S., Lister, C., Swiezewski, S., and Dean, C. (2010). Targeted 3' processing of antisense transcripts triggers Arabidopsis FLC chromatin silencing. Science 327, 94-97. doi: 10.1126/science.1180278

Liu, S., Sehgal, S. K., Li, J., Lin, M., Trick, H. N., Yu, J., et al. (2013). Cloning and characterization of a critical regulator for pre-harvest sprouting in wheat. Genetics 195, 263-273. doi: 10.1534/genetics.113.152330

Liu, Y., Geyer, R., van Zanten, M., Carles, A., Li, Y., Hörold, A., et al. (2011). Identification of the Arabidopsis REDUCED DORMANCY 2 gene uncovers a role for the polymerase associated factor 1 complex in seed dormancy. PLoS ONE 6:e22241. doi: 10.1371/journal.pone.0022241

Liu, Y., Koornneef, M., and Soppe, W. J. J. (2007). The absence of histone H2B monoubiquitination in the Arabidopsis hubl ( $r$ do4) mutant reveals a role for chromatin remodeling in seed dormancy. Plant Cell 19, 433-444. doi: 10.1105/tpc.106.049221

Mallory, A., and Vaucheret, H. (2010). Form, function, and regulation of ARGONAUTE proteins. Plant Cell 22, 3879-3889. doi: 10.1105/tpc.110.080671

Martinez-Andujar, C., Ordiz, M. I., Huang, Z., Nonogaki, M., Beachy, R. N., and Nonogaki, H. (2011). Induction of 9-cis-epoxycarotenoid dioxygenase in Arabidopsis thaliana seeds enhances seed dormancy. Proc. Natl. Acad. Sci. U.S.A. 108, 17225-17229. doi: 10.1073/pnas.1112151108

Martinez-Andujar, C., Pluskota, W. E., Bassel, G. W., Asahina, M., Pupel, P., Nguyen, T. T., et al. (2012). Mechanisms of hormonal regulation of endosperm cap-specific gene expression in tomato seeds. Plant J. 71, 575-586. doi: 10.1111/j.1365-313X.2012.05010.x

Miatton, E. (2012). Characterization of PDF1 and Its Interaction With DELAY OF GERMINATION1 (DOG1) in the Control of Seed Dormancy in Arabidopsis thaliana. Köln: University of Köln.

Mikami, K., Takase, H., Tabata, T., and Iwabuchi, M. (1989). Multiplicity of the DNA-binding protein HBP-1 specific to the conserved hexameric sequence ACGTCA in various plant gene promoters. FEBS Lett. 256, 67-70. doi: 10.1016/0014-5793(89)81719-3

Molitor, A. M., Bu, Z., Yu, Y., and Shen, W. H. (2014). Arabidopsis AL PHDPRC1 complexes promote seed germination through H3K4me3-to-H3K27me3 chromatin state switch in repression of seed developmental genes. PLoS Genet. 10:e1004091. doi: 10.1371/journal.pgen.1004091

Mortensen, S. A., and Grasser, K. D. (2014). The seed dormancy defect of Arabidopsis mutants lacking the transcript elongation factor TFIIS is caused by reduced expression of the DOG1 gene. FEBS Lett. 588, 47-51. doi: 10.1016/j.febslet.2013.10.047

Muller, K., Bouyer, D., Schnittger, A., and Kermode, A. R. (2012). Evolutionarily conserved histone methylation dynamics during seed life-cycle transitions. PLoS ONE 7:e51532. doi: 10.1371/journal.pone.0051532

Nakabayashi, K., Bartsch, M., Xiang, Y., Miatton, E., Pellengahr, S., Yano, R., et al. (2012). The time required for dormancy release in Arabidopsis is determined by DELAY OF GERMINATION1 protein levels in freshly harvested seeds. Plant Cell 24, 2826-2838. doi: 10.1105/tpc.112.100214

Nakamura, S., Abe, F., Kawahigashi, H., Nakazono, K., Tagiri, A., Matsumoto, T., et al. (2011). A wheat homolog of MOTHER OF FT AND TFL1 acts in the regulation of germination. Plant Cell 23, 3215-3229. doi: 10.1105/tpc.111. 088492
Nakanishi, S., Lee, J. S., Gardner, K. E., Gardner, J. M., Takahashi, Y. H., Chandrasekharan, M. B., et al. (2009). Histone H2BK123 monoubiquitination is the critical determinant for $\mathrm{H} 3 \mathrm{~K} 4$ and $\mathrm{H} 3 \mathrm{~K} 79$ trimethylation by COMPASS and Dot1. J. Cell Biol. 186, 371-377. doi: 10.1083/jcb. 200906005

Nakayama, T., Ohtsubo, N., Mikami, K., Kawata, T., Tabata, T., Kanazawa, H., et al. (1989). Cisacting sequences that modulate transcription of wheat histone $\mathrm{H} 3$ and 3'processing of H3 premature mRNA. Plant Cell Physiol. 30, 825-832.

Ni, B. R., and Bradford, K. J. (1993). Germination and dormancy of abscisic acidand gibberellin-deficient mutant tomato (Lycopersicon esculentum) seeds (sensitivity of germination to abscisic acid, gibberellin, and water potential). Plant Physiol. 101, 607-617.

Nonogaki, H., Gee, O. H., and Bradford, K. J. (2000). A germination-specific endobeta -mannanase gene is expressed in the micropylar endosperm cap of tomato seeds. Plant Physiol. 123, 1235-1246. doi: 10.1104/pp.123.4.1235

Nonogaki, H., Nomaguchi, M., Okumoto, N., Kaneko, Y., Matsushima, H., and Morohashi, M. (1998). Temporal and spatial pattern of the biochemical activation of the endosperm during and following imbibition of tomato seeds. Physiol. Plant. 102, 236-242. doi: 10.1034/j.1399-3054.1998.1020211.x

Nonogaki, M., Sall, K., Nambara, E., and Nonogaki, H. (2014). Amplification of ABA biosynthesis and signaling through a positive feedback mechanism in seeds. Plant J. 78, 527-539. doi: 10.1111/tpj.12472

Ogawa, M., Hanada, A., Yamauchi, Y., Kuwahara, A., Kamiya, Y., and Yamaguchi, S. (2003). Gibberellin biosynthesis and response during Arabidopsis seed germination. Plant Cell 15, 1591-1604. doi: 10.1105/tpc.011650

Oh, S., Zhang, H., Ludwig, P., and van Nocker, S. (2004). A mechanism related to the yeast transcriptional regulator Paflc is required for expression of the Arabidopsis FLC/MAF MADS box gene family. Plant Cell 16, 2940-2953. doi: 10.1105/tpc. 104.026062

Onodera, Y., Haag, J. R., Ream, T., Costa Nunes, P., Pontes, O., and Pikaard, C. S. (2005). Plant nuclear RNA polymerase IV mediates siRNA and DNA methylation-dependent heterochromatin formation. Cell 120, 613-622. doi: 10.1016/j.cell.2005.02.007

Peeters, A. J. M., Blankestijn-de Vries, H., Hanhart, C. J., Léon-Kloosterziel, K. M., Zeevaart, J. A. D., and Koornneef, M. (2002). Characterization of mutants with reduced seed dormancy at two novel $r$ do loci and a further characterization of rdo1 and rdo2 in Arabidopsis. Physiol. Plant. 115, 604-612. doi: 10.1034/j.13993054.2002.1150415.x

Penheiter, K. L., Washburn, T. M., Porter, S. E., Hoffman, M. G., and Jaehning, J. A. (2005). A posttranscriptional role for the yeast Paf1-RNA polymerase II complex is revealed by identification of primary targets. Mol. Cell 20, 213-223. doi: 10.1016/j.molcel.2005.08.023

Perrella, G., Lopez-Vernaza, M. A., Carr, C., Sani, E., Gossele, V., Verduyn, C., et al. (2013). Histone deacetylase complex1 expression level titrates plant growth and abscisic acid sensitivity in Arabidopsis. Plant Cell 25, 3491-3505. doi: 10.1105/tpc.113.114835

Piskurewicz, U., Jikumaru, Y., Kinoshita, N., Nambara, E., Kamiya, Y., and LopezMolina, L. (2008). The gibberellic acid signaling repressor RGL2 inhibits Arabidopsis seed germination by stimulating abscisic acid synthesis and ABI5 activity. Plant Cell 20, 2729-2745. doi: 10.1105/tpc.108.061515

Porter, S. E., Penheiter, K. L., and Jaehning, J. A. (2005). Separation of the Saccharomyces cerevisiae Pafl complex from RNA polymerase II results in changes in its subnuclear localization. Eukaryotic Cell 4, 209-220. doi: 10.1128/EC.4.1.209-220.2005

Qi, Y., He, X., Wang, X.-J., Kohany, O., Jurka, J., and Hannon, G. J. (2006). Distinct catalytic and non-catalytic roles of ARGONAUTE4 in RNA-directed DNA methylation. Nature 443, 1008-1012. doi: 10.1038/nature05198

Rea, S., Eisenhaber, F., O'Carroll, D., Strahl, B. D., Sun, Z.-W., Schmid, M., et al. (2000). Regulation of chromatin structure by site-specific histone H3 methyltransferases. Nature 406, 593-599. doi: 10.1038/35020506

Richon, V. M., and O’Brien, J. P. (2002). Histone deacetylase inhibitors: a new class of potential therapeutic agents for cancer treatment. Clin. Cancer Res. 8, 718-728, 662-664.

Saunders, A., Core, L. J., and Lis, J. T. (2006). Breaking barriers to transcription elongation. Nat. Rev. Mol. Cell Biol. 7, 557-567. doi: 10.1038/nrm1981

Schramm, E., Nelson, S., Kidwell, K., and Steber, C. (2013). Increased ABA sensitivity results in higher seed dormancy in soft white spring wheat cultivar 'Zak.' Theor. Appl. Genet. 126, 791-803. doi: 10.1007/s00122-0122018-0 
Seo, M., Nambara, E., Choi, G., and Yamaguchi, S. (2009). Interaction of light and hormone signals in germinating seeds. Plant Mol. Biol. 69, 463-472. doi: 10.1007/s11103-008-9429-y

Shu, K., Zhang, H., Wang, S., Chen, M., Wu, Y., Tang, S., et al. (2013). ABI4 regulates primary seed dormancy by regulating the biogenesis of abscisic acid and gibberellins in Arabidopsis. PLoS Genet. 9:e1003577. doi: 10.1371/journal.pgen.1003577

Simon, J. A., and Kingston, R. E. (2009). Mechanisms of Polycomb gene silencing: knowns and unknowns. Nat. Rev. Mol. Cell Biol. 10, 697-708. doi: $10.1038 / \mathrm{nrm} 2763$

Singh, M., and Singh, J. (2012). Seed development-related expression of ARGONAUTE4_9 class of genes in barley: possible role in seed dormancy. Euphytica 188, 123-129. doi: 10.1007/s10681-012-0624-1

Singh, M., Singh, S., Randhawa, H., and Singh, J. (2013). Polymorphic homoeolog of key gene of RdDM pathway, ARGONAUTE4_9 class is associated with preharvest sprouting in wheat (Triticum aestivum L.). PLOS ONE 8:e77009. doi: 10.1371/journal.pone.0077009

Sugimoto, K., Takeuchi, Y., Ebana, K., Miyao, A., Hirochika, H., Hara, N., et al. (2010). Molecular cloning of $S d r 4$, a regulator involved in seed dormancy and domestication of rice. Proc. Natl. Acad. Sci. U.S.A. 107, 5792-5797. doi: 10.1073/pnas.0911965107

Sun, Q., Csorba, T., Skourti-Stathaki, K., Proudfoot, N. J., and Dean, C. (2013). Rloop stabilization represses antisense transcription at the Arabidopsis FLC locus. Science 340, 619-621. doi: 10.1126/science. 1234848

Sun, Z.-W., and Allis, C. D. (2002). Ubiquitination of histone H2B regulates H3 methylation and gene silencing in yeast. Nature 418, 104-108. doi: 10.1038 /nature00883

Swiezewski, S., Liu, F., Magusin, A., and Dean, C. (2009). Cold-induced silencing by long antisense transcripts of an Arabidopsis Polycomb target. Nature 462, 799-802. doi: 10.1038/nature08618

Tabata, T., Nakayama, T., Mikami, K., and Iwabuchi, M. (1991). HBP-1a and HBP1b: leucine zipper-type transcription factors of wheat. EMBO J. 10, 1459-1467.

To, T. K., Kim, J.-M., Matsui, A., Kurihara, Y., Morosawa, T., Ishida, J., et al. (2011). Arabidopsis HDA6 regulates locus-directed heterochromatin silencing in cooperation with MET1. PLoS Genet. 7:e1002055. doi: 10.1371/journal.pgen.1002055

Tran, R. K., Zilberman, D., de Bustos, C., Ditt, R. F., Henikoff, J. G., Lindroth, A. M., et al. (2005). Chromatin and siRNA pathways cooperate to maintain DNA methylation of small transposable elements in Arabidopsis. Genome Biol. 6, R90. doi: 10.1186/gb-2005-6-11-r90

Voegele, A., Linkies, A., Muller, K., and Leubner-Metzger, G. (2011). Members of the gibberellin receptor gene family GID1 (GIBBERELLIN INSENSITIVE $D W A R F 1)$ play distinct roles during Lepidium sativum and Arabidopsis thaliana seed germination. J. Exp. Bot. 62, 5131-5147. doi: 10.1093/jxb/ err214

Wang, Z., Cao, H., Sun, Y., Li, X., Chen, F., Carles, A., et al. (2013). Arabidopsis paired amphipathic helix proteins SNL1 and SNL2 redundantly regulate primary seed dormancy via abscisic acid-ethylene antagonism mediated by histone deacetylation. Plant Cell 25, 149-166. doi: 10.1105/tpc.112. 108191

Wierzbicki, A. T. (2012). The role of long non-coding RNA in transcriptional gene silencing. Curr. Opin. Plant Biol. 15, 517-522. doi: 10.1016/j.pbi.2012.08.008

Wierzbicki, A. T., Haag, J. R., and Pikaard, C. S. (2008). Noncoding transcription by RNA polymerase $\mathrm{Pol} \mathrm{IVb} / \mathrm{Pol} \mathrm{V}$ mediates transcriptional silencing of overlapping and adjacent genes. Cell 135, 635-648. doi: 10.1016/j.cell.2008.09.035

Wierzbicki, A. T., Ream, T. S., Haag, J. R., and Pikaard, C. S. (2009). RNA polymerase V transcription guides ARGONAUTE4 to chromatin. Nat. Genet. 41, 630-634. doi: 10.1038/ng.365
Xi, W., Liu, C., Hou, X., and Yu, H. (2010). MOTHER OF FT AND TFL1 regulates seed germination through a negative feedback loop modulating ABA signaling in Arabidopsis. Plant Cell 22, 1733-1748. doi: 10.1105/tpc.109.073072

Xie, Z., Johansen, L. K., Gustafson, A. M., Kasschau, K. D., Lellis, A. D., Zilberman, D., et al. (2004). Genetic and functional diversification of small RNA pathways in plants. PLoS Biol. 2:E104. doi: 10.1371/journal.pbio.0020104

Yamada, K., Lim, J., Dale, J. M., Chen, H., Shinn, P., Palm, C. J., et al. (2003). Empirical analysis of transcriptional activity in the Arabidopsis genome. Science 302, 842-846. doi: 10.1126/science. 1088305

Yamaguchi, S., Kamiya, Y., and Sun, T. (2001). Distinct cell-specific expression patterns of early and late gibberellin biosynthetic genes during Arabidopsis seed germination. Plant J. 28, 443-453. doi: 10.1046/j.1365-313X.2001.01168.x

Yamauchi, Y., Ogawa, M., Kuwahara, A., Hanada, A., Kamiya, Y., and Yamaguchi, S. (2004). Activation of gibberellin biosynthesis and response pathways by low temperature during imbibition of Arabidopsis thaliana seeds. Plant Cell 16, 367-378. doi: 10.1105/tpc.018143

Yano, R., Takebayashi, Y., Nambara, E., Kamiya, Y., and Seo, M. (2013). Combining association mapping and transcriptomics identify $H D 2 B$ histone deacetylase as a genetic factor associated with seed dormancy in Arabidopsis thaliana. Plant J. 74, 815-828. doi: 10.1111/tpj.12167

Yu, X., and Michaels, S. D. (2010). The Arabidopsis Paflc complex component CDC73 participates in the modification of FLOWERING LOCUS C chromatin. Plant Physiol. 153, 1074-1084. doi: 10.1104/pp.110.158386

Zentella, R., Zhang, Z.-L., Park, M., Thomas, S. G., Endo, A., Murase, K., et al. (2007). Global analysis of DELLA direct targets in early gibberellin signaling in Arabidopsis. Plant Cell 19, 3037-3057. doi: 10.1105/tpc.107.054999

Zhang, H., and Van Nocker, S. (2002). The VERNALIZATION INDEPENDENCE 4 gene encodes a novel regulator of FLOWERING LOCUS C. Plant J. 31, 663-673. doi: 10.1046/j.1365-313X.2002.01380.x

Zheng, J., Chen, F., Wang, Z., Cao, H., Li, X., Deng, X., et al. (2012). A novel role for histone methyltransferase KYP/SUVH4 in the control of Arabidopsis primary seed dormancy. New Phytol. 193, 605-616. doi: 10.1111/j.14698137.2011.03969.x

Zhu, B., Zheng, Y., Pham, A.-D., Mandal, S. S., Erdjument-Bromage, H., Tempst, P., et al. (2005). Monoubiquitination of human histone H2B: the factors involved and their roles in HOX gene regulation. Mol. Cell 20, 601-611. doi: 10.1016/j.molcel.2005.09.025

Zilberman, D., Cao, X., Johansen, L. K., Xie, Z., Carrington, J. C., and Jacobsen, S. E. (2004). Role of Arabidopsis ARGONAUTE4 in RNA-directed DNA methylation triggered by inverted repeats. Curr. Biol. 14, 1214-1220. doi: 10.1016/j.cub.2004.06.055

Conflict of Interest Statement: A patent application has been filed for a technology described in this article. The author declares that the research was conducted in the absence of any commercial or financial relationships that could be construed as a potential conflict of interest.

Received: 21 March 2014; accepted: 10 May 2014; published online: 28 May 2014 Citation: Nonogaki H (2014) Seed dormancy and germination-emerging mechanisms and new hypotheses. Front. Plant Sci. 5:233. doi: 10.3389/fpls.2014.00233

This article was submitted to Plant Evolution and Development, a section of the journal Frontiers in Plant Science.

Copyright (C) 2014 Nonogaki. This is an open-access article distributed under the terms of the Creative Commons Attribution License (CC BY). The use, distribution or reproduction in other forums is permitted, provided the original author(s) or licensor are credited and that the original publication in this journal is cited, in accordance with accepted academic practice. No use, distribution or reproduction is permitted which does not comply with these terms. 